\title{
Retrospective analysis of selected aspects of public blood transfusion service as a starting point for assessment of the status of transfusion medicine in Poland Part 1: Demographic characteristics of the donor population reporting for blood donation to Polish Regional Blood Transfusion Centers in the period 2005-2017
}

\author{
Agata Mikołowska®, Jolanta Antoniewicz-Papis (D) \\ Institute of Hematology and Transfusion Medicine (IHTM), Warsaw, Poland
}

\begin{abstract}
Summary
Background: The ongoing demographic changes in Poland affect the number of donors and donations with direct impact on provision of blood and blood components for transfusion. With predicted population-decline, the number of potential donors is likely to decrease while the demand for blood is bound to increase as more people will require blood therapy. The structure of the Polish donor population reporting for blood donation is not uniform, moreover it has undergone additional changes within the study period. So it seems justified to perform in-depth analysis of the dynamics of changes in the number and structure of donor group as well as determine the direction and intensity of these changes in spatial and temporal terms. Identification of the possible causes of change is also important. Aim: presentation of the structure characteristics of the donor group who reported at the Polish regional blood transfusion centers (RBTCs) in the period 2005-2017 with the intention of donating blood/ blood components.
\end{abstract}

Materials and methods: Analyses of available data-sets - annual reports from 21 Polish RBTCs forwarded to the IHTM. The following tools were used for statistical analysis: Microsoft Office: Access and Excel, Microsoft Power Business Intelligence (Power BI) software and STATISTICA version 13.3 software (TIBCO Software Inc.).

Results: In 2005-2017 the total number of donors amounted to 8691611 including 2542621 (29.3\%) women and 6148990 (70.7\%) men. Voluntary non-remunerated donors were estimated at 8684069 (99.9\%). The average annual number of donors per RBTC was 31837 and included 31809 voluntary non-remunerated donors; 22524 men and 9314 women. Countrywide, the highest number was reported for the period 2011-2013; 701882 (8.08\%), 707578 (8.14\%) and 706246 (8.13\%) for respective years and for the period 2015-2016 the numbers were 718887 (8.27\%) and 706476 (8.13\%) respectively. The highest number for the period was reported by 5 RBTCs: Warsaw (951 068 - 10.94\%), Katowice (748 841; 8.62\%), Poznan (702 087; 8.08\%), Krakow (651 057; 7.49\%) and Wroclaw (556 357; 6.40\%).

Correspondence address: mgr Agata Mikołowska, Institute of Hematology and Transfusion Medicine, Warsaw, Indiry Gandhi Street 14, 02-776 Warsaw, phone (22) 34963 87, e-mail: amikolowska@ihit.waw.pl

Translation: mgr Krystyna Dudziak 
In the number of 2352099 donors who have recently reported for blood donation at the RBTCs the 25-44 age group was the largest (48\%). The least numerous was the 45-65 age group 548885 (ca. 11\%). There were 2030692 donors in the 18-24 age category ( $>41 \%$ of the total donor-population).Trend-analysis demonstrated an upward tendency for the category of 25-44 age donors and a downward one for the 18-24 age category. No explicit trend was observed for the 45-65 age group.

Conclusion: The number of blood donations in Poland has recently reached the limit of approximately 1200000 donations per year. To exceed this limit will be no easy task. All efforts must therefore be focused on promoting people's willingness to donate blood. The analysis indicates a falling tendency for the 18-24 age group and a rising one for higher age groups, which only raises concern for the future. The priority is therefore to motivate people of all agegroups to donate blood and become multiple donors with special emphasis however on the very young people as they are the potential source for many years to come. Promotion of voluntary non-remunerated blood-donation among children is equally important; in several years' time transfusion medicine will depend on their willingness to donate blood.

Key words: demographic changes, blood donors, blood transfusion, Regional Blood Transfusion Center

J. Transf. Med. 2020; 13: 67-103

\section{Introduction}

In Poland, transfusion medicine is part of the public blood transfusion service (BTS) and an integral part of the national health care system.

The health care system is part of the public health system defined by World Health Organization (WHO) as: "an organized effort by society, primarily through its public institutions, undertaken to improve, promote, protect and restore the health of the population through collective action. It includes services such as health situation analysis, epidemiological surveillance, health promotion, prevention, control of infectious diseases, environmental protection and sanitation, disaster and health preparedness and response, and occupational health, among others" [1].

The fundamental goal of modern blood transfusion service worldwide is to provide adequate supplies of safe blood and blood components to meet transfusion needs as well as of raw material for manufacturing of blood products. It is also a precondition to effective functioning of the healthcare system.

According to the "Population forecast for 2014-2050 " by the Central Statistical Office of Poland (GUS), in 2050 the population of the country will amount to 33 million 951 thousand, which is a decrease by 4.55 million (12\%) as compared to the status for December 31, 2013 (adopted as starting point for assumptions and analyses of predicted directions in demographic changes) [2].
Ageing society and low birth rate are the main problems that Poland is currently facing. According to recent forecasts, no significant changes are to be expected in the nearest future. However, as compared to other member countries of the European Union (EU), Poland is still perceived as a relatively young society. According to Eurostat data, the median age of the Polish population in 2018 was 40.6 years, while for all $\mathrm{EU}$ member states combined, it was almost 43.1 years [3].

Demographic changes observed in the Polish population, especially ageing, have direct impact on the number of donors and donations, and ultimately on the supply of blood and blood components for transfusion therapy. The population-decrease may correlate with decrease in the number of potential blood donors. At the same time, the demand for blood and blood components is likely to increase as the number of people who may require blood and blood component transfusion will grow.

In Figure 1, the projected total population in Poland is compared with working-age population for the period 2020-2050. As the Central Statistical Office (GUS) had no available prognostic age-data broken down into individual years, the working-age group of 18 until retirement (65 years for women and 67 for men) was selected as closest to the eligibility age for blood donation (18-65). Data demonstrates that by 2050 the total population will decrease by over 4 million, while the number of working-age people by about 5 million.

Changes will be induced not only by lower birth rate but also by factors such as: emigration 


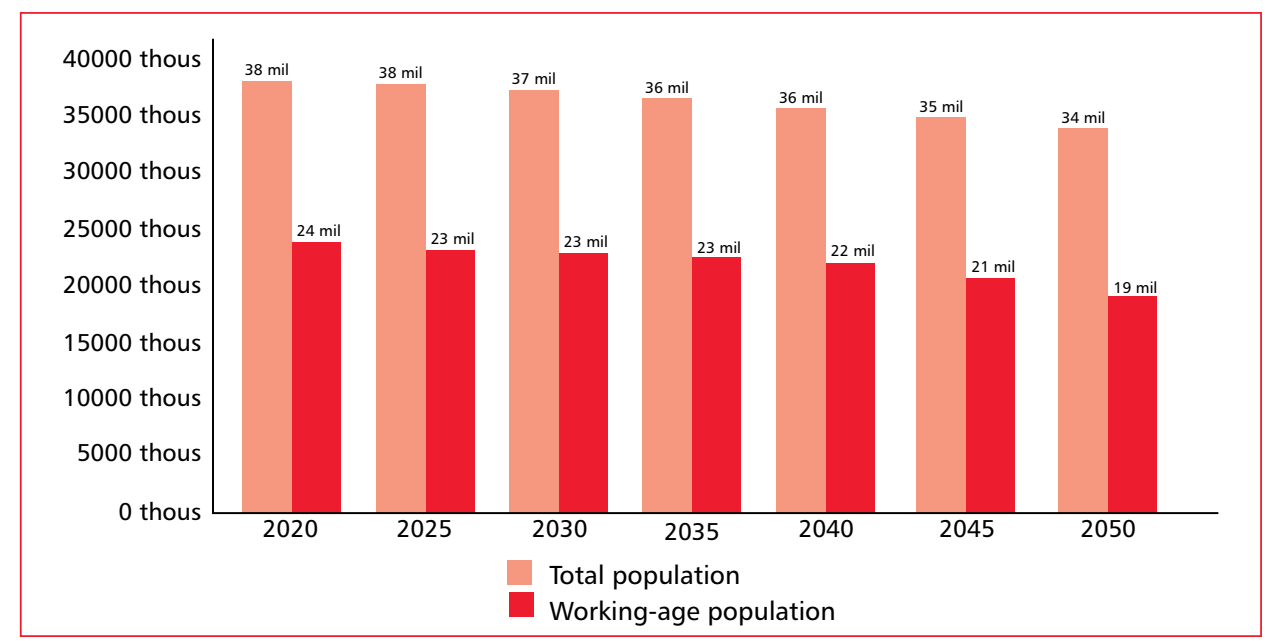

Figure 1. Projected total population vs working-age population in 2020-2050

of young people, pace of everyday life and healthaffecting conditions, all of which contribute to narrowing the number of potential blood donors.

It is worth noting that people who reported in Regional Blood Transfusion Centers (RBTCs) with the intention of donating blood for clinical use were not all found eligible for donation. Restrictive donor qualification criteria is the first and extremely important step towards provision of safe blood and ultimately for safe-guard of the recipients.

It is known for a fact that the structure of the population reporting to Polish RBTCs for blood donation is heterogeneous, furthermore, it was necessary to take into account certain changes that occurred during the period under study.

There is therefore a justified need for in-depth analysis of the dynamics of changes in the number and structure of donor population, both the people who expressed the will to donate as well as those who were found eligible for donation. It is important to determine the direction and intensity of the phenomenon in both spatial and temporal terms. Equally important are attempts at identification of the likely reasons for the changes.

\section{Aim}

This reviw is the first of a series of publications devoted to the description of selected activities of Polish public BTS with the aim of assessing the status of transfusion medicine in Poland. In preparation are articles on: demographic structure of the donor population eligible for donation of blood and blood components for clinical use, characteristics of the donations, blood management and analysis of the status of red blood cell inventories.

The purpose of this publication was to present the characteristics of donor-population which reported in RBTCs in the period 2005-2017 with the intention of donating blood/blood components, no matter whether the donation was finalized or not.

\section{Materials and methods}

The analyses were based on available data sets. The secondary statistical material were the reports from RBTCs sent each year to the Institute of Hematology and Transfusion Medicine (IHTM). All analyses referred to the territory of Poland.

The analyses included data from 21 RBTCs which - together with the Military Blood Transfusion Center and the Blood Transfusion Center of the Ministry of the Internal Affairs and Administration - are part of a more general collectivity. Although partial, the analysis of the data from 21 RBTCs is undoubtedly based on a sample that can be considered representative, as the field of activity of these 21 centers covers the territory of the whole country and the differences in the scope and schedule for implementation of legal and administrative changes are reduced to minimum due to identical organizational structure and legal subordination. The remaining two centers (Military Blood Transfusion Center and the Blood Transfusion Center of the Ministry of the Internal Affairs and Administration) are not subordinate to the Minister of Health, which imposed restrictions on access to information required for the study. According to available data, these two blood trans- 
fusion centers are responsible for merely $3.8 \%$ of Polish donors, so disregarding them did not affect the analysis.

The raw material for statistical analysis, i.e. data assembled in its original form, was subjected to special processing and preparation. Initial verification was performed in terms of data completeness and accuracy; the data was then organized and grouped for the purpose of analysis and the results were presented in form of tables and diagrams. A detailed description of the steps taken to prepare the material for analysis will be published in a separate review, solely devoted to the issue.

MS Access and MS Excel of the Microsoft Office professional suite were used for the purpose of data-preparation and analysis of statistical material. Microsoft Power Business Intelligence (Power BI) software was also put to use. Additionally, STATISTICA software version 13.3 (TIBCO Software Inc.) was used to perform all descriptive statistics presented in this work.

\section{Results}

\section{Working-age population}

As already mentioned, in order to estimate the percentage of people who reported to RBTCs to donate blood versus the population of potential blood donors, we relied on GUS-data for the working-age population (18 until retirement i.e. 65 for women and 67 for men.); this group was considered closest to the 18-65 age-category eligible for blood donation.

Figure 2 and Table 1 compare the total population of Poland, the working-age population and population of people who reported for blood/blood component donations to Polish RBTCs in the period 2005-2017.

It follows that merely $3 \%$ of the population of potential blood donors reported at the RBTCs to donate blood/blood components; their characteristics are presented below.

\section{Characteristics of donors who reported to donate blood/blood components in the period 2005-2017}

\section{Total donor-population}

Table 2 presents the basic data referring to the population of donors who reported at RBTCs in 2005-2017 with the intention of donating blood/ /blood components. During the study period, the total number of donors (daw_zgl_krew) was estimated at 8691611 and included 2542621 (29.3\%) women (daw_zgl_krew_K) and 6148990 (70.7\%) men (daw_zgl_krew_M). The number of voluntary non-remunerated donors (daw_zgl_krew_h) amounted to 7885266 , which is $90 . \overline{7} \%$ of the total number of donors who reported at RBTCs with the intention of donating blood/blood components. In addition, there were also responders to donation appeal (previously named "family" donors) (daw zgl_krew_r). The group of responders to donation appeal was reviewed separately, although people from this group are also classified as voluntary non-remunerated donors. According to Table 2, the total number of responders to donation appeals was estimated at 778803 (i.e. $8.9 \%$ of the total number of donors).

The annual average total number of donors per RBTC was 31 837; 28957 - voluntary non-remunerated donors, 2961 responders to donation appeal, 22524 - male donors and 9314 female donors.

Table 3 presents the number of donors who reported in RBTCs with the intention of donating blood/blood components broken down into years. The highest numbers were reported for the period 2011-2013 [701 882 (8.08\%), 707578 (8.14\%) and $706246(8.13 \%)$ respectively] as well as for 2015-2016 (718 887 (8.27\%) and 706476 (8.13\%). The lowest number was recorded in 2005 for RBTC in Slupsk - 8365 and the highest in 2015 for RBTC in Warsaw - 76177 donors (Table 4).

Characteristics of the whole donor population who reported to donate blood/blood components in 2005-2017 is presented in Table 4, broken down into RBTCs. The largest number of donors reported in 5 RBTCs: Warsaw (951 068; 10.94\%), Katowice (748 841; 8.62\%), Poznan (702 087; $8.08 \%)$, Krakow (651 057; 7.49\% and Wroclaw (556 357; 6.40\%) (Table 4).

\section{Voluntary non-remunerated blood donors}

Data referring to voluntary non-remunerated donors who reported in RBTCs with the intention of donating blood/blood components broken down into years of the study-period is presented in Table 5. Countrywide, the highest number of voluntary non-remunerated donors was recorded in 2011-2012 (645 435 (8.19\%) and $647479(8.21 \%)$ and in 2014-2016 (643 180 (8.16\%), 669581 $(8.49 \%)$ and $648235(8.22 \%)$ respectively. The lowest number was recorded in 2005 at RBTC in Słupsk - 8342, while the highest in 2015 - 66 000 at RBTC in Warsaw (Table 6).

Table 6 presents the characteristics of the total population of voluntary non-remunerated donors who reported for donation of blood/blood 


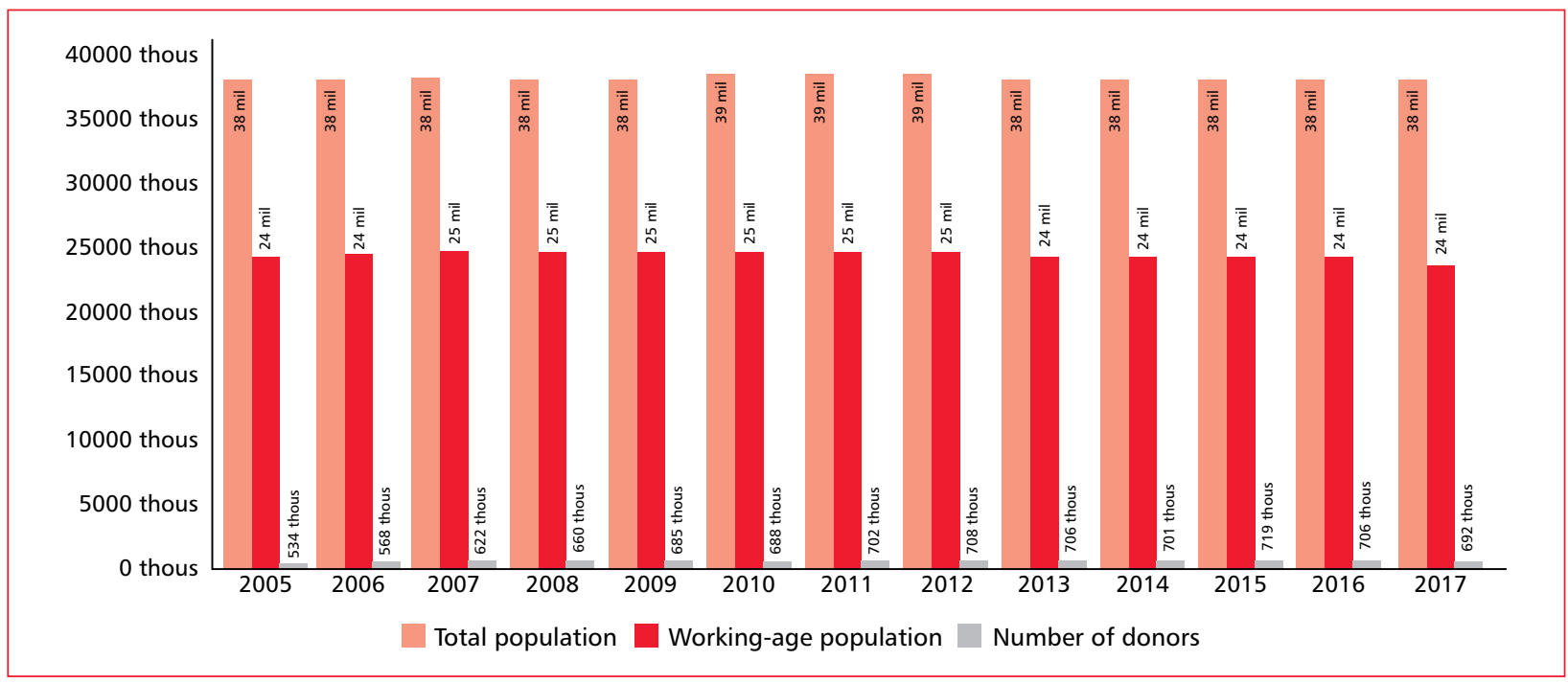

Figure 2. Total population, working-age population and population of people who reported to Polish RBTCs for donation of blood/blood components (2005-2017)

Table 1. Numbers and percentage of people reporting for blood donation vs population of potential donors of blood/blood components in the consecutive years of 2005-2017

\begin{tabular}{lcccc}
\hline Year & Total population & Working-age population & $\begin{array}{c}\text { Donors reporting } \\
\text { for donation }\end{array}$ & $\begin{array}{c}\% \text { of donors reporting } \\
\text { for donation }\end{array}$ \\
\hline 2005 & 38157055 & 24405034 & 534342 & $2.19 \%$ \\
2006 & 38125479 & 24481670 & 567760 & $2.32 \%$ \\
2007 & 38115641 & 24545254 & 622357 & $2.54 \%$ \\
2008 & 38135876 & 24590475 & 660056 & $2.68 \%$ \\
2009 & 38167329 & 24624443 & 684908 & $2.78 \%$ \\
2010 & 38529866 & 24831001 & 688272 & $2.77 \%$ \\
2011 & 38538447 & 24738527 & 701882 & $2.84 \%$ \\
2012 & 38533299 & 24605558 & 707578 & $2.88 \%$ \\
2013 & 38495659 & 24422146 & 706246 & $2.89 \%$ \\
2014 & 38478602 & 24230162 & 700666 & $2.89 \%$ \\
2015 & 38437239 & 24002168 & 718887 & $3.00 \%$ \\
2016 & 38432992 & 23767614 & 706476 & $2.97 \%$ \\
2017 & 38433558 & 23517643 & 692181 & $2.94 \%$ \\
Total & 498581042 & 316761695 & 8691611 & $2.74 \%$ \\
\hline
\end{tabular}

components in the period 2005-2017 broken down into RBTCs. The highest numbers were recorded for 5 RBTCs: in Warsaw (771 038; 9.78\%), Katowice (731 392; 9.28\%), Poznan (565 934; 7.18\%), Krakow (646 802; 8.20\%) and Wroclaw (505 304; $6.41 \%)$.

\section{Responders to donation appeal}

Table 7 presents data for responders to donation appeal who reported at RBTCs broken down into years. Countrywide, the highest number was reported in the period 2007-2010: 73627 (9.45\%), 79470 (10.20\%), 77435 (9.94\%), 64335 (8.26\%) respectively and in $2013-74084(9.51 \%)$. The highest number was 19872 - recorded in RBTC in Warsaw in 2008 (Table 8).

\section{Comparison between donor groups}

Figure 3 compares donor population who reported at RBTCs (in the period 2005-2017) with the intention of donating blood/blood components with the group of voluntary non-remunerated 
Table 2. Characteristics of the whole donor population who reported at RBTCs to donate blood/blood components (2005-2017)

\begin{tabular}{lccccc}
\hline Variable & Average & Median & Total & Min & Max \\
\hline daw_zgl_krew & 31837 & 27434 & 8691611 & 8365 & 76177 \\
daw_zgl_krew_h & 28884 & 26546 & 7885266 & 8342 & 66000 \\
daw_zgl_krew_r & 2961 & 944 & 778803 & 0 & 19872 \\
daw_zgl_krew_K & 9314 & 7590 & 2542621 & 958 & 26300 \\
daw_zgl_krew_M & 22524 & 19964 & 6148990 & 7407 & 54792 \\
\hline
\end{tabular}

daw_zgl_krew — total number of donors; daw_zgl_krew_h — voluntary non-remunerated donors; daw_zgl_krew_r — responders to donation appeal; daw_zgl_krew_K - female donors; daw_zgl_krew_M - male donors

Table 3. Characteristics of the whole donor population who reported at RBTCs to donate blood/blood components, broken down into years

\begin{tabular}{lccccccc}
\hline Variable & Year & Average & Median & Total & Min & Max & $\%$ total \\
\hline daw_zgl_krew & 2005 & 25445 & 21490 & 534342 & 8365 & 63944 & $6.15 \%$ \\
daw_zgl_krew & 2006 & 27036 & 22849 & 567760 & 9840 & 66888 & $6.53 \%$ \\
daw_zgl_krew & 2007 & 29636 & 25924 & 622357 & 12022 & 74451 & $7.16 \%$ \\
daw_zgl_krew & 2008 & 31431 & 26661 & 660056 & 12645 & 75888 & $7.59 \%$ \\
daw_zgl_krew & 2009 & 32615 & 26062 & 684908 & 10915 & 73813 & $7.88 \%$ \\
daw_zgl_krew & 2010 & 32775 & 25932 & 688272 & 12415 & 74164 & $7.92 \%$ \\
daw_zgl_krew & 2011 & 33423 & 26046 & 701882 & 12136 & 74710 & $8.08 \%$ \\
daw_zgl_krew & 2012 & 33694 & 26914 & 707578 & 12250 & 75079 & $8.14 \%$ \\
daw_zgl_krew & 2013 & 33631 & 27557 & 706246 & 12752 & 75019 & $8.13 \%$ \\
daw_zgl_krew & 2014 & 33365 & 28953 & 700666 & 12891 & 75651 & $8.06 \%$ \\
daw_zgl_krew & 2015 & 34233 & 31779 & 718887 & 13897 & 76177 & $8.27 \%$ \\
daw_zgl_krew & 2016 & 33642 & 31428 & 706476 & 12730 & 72894 & $8.13 \%$ \\
daw_zgl_krew & 2017 & 32961 & 31047 & 692181 & 12573 & 72390 & $7.96 \%$ \\
Total & & & & 8691611 & & & $100 \%$ \\
\hline
\end{tabular}

daw_zgl_krew — total number of donors

donors. The long-term trend line for both variables indicates an upward trend for both donor populations.

Figure 4 is a comparison between donors who reported at RBTCs to donate blood/blood components with the number of voluntary nonremunerated donors and responders to donation appeal. In the period 2005-2017, the average number of donors who came to donate blood/blood components per RBTC was 413886 , voluntary non-remunerated donors - 375489 and 37086 responders to donation appeal. In 9/21 RBTCs (Warsaw, Katowice, Poznan, Krakow, Wroclaw, Lodz, Bydgoszcz, Lublin and Gdansk) the number of donors willing to donate blood exceeded the average for the whole country. For voluntary non-remunerated donors, the number was higher than the national average in 10/21 RBTCs (Warsaw, Katowice, Poznan, Krakow, Wroclaw, Lodz, Bydgoszcz, Lublin, Gdansk and Bialystok). For responders to donation appeal, the number was higher than the national average in 8/21 RBTCs (Warsaw, Poznan, Wroclaw, Lodz, Bydgoszcz, Lublin, Gdansk and Kielce).

\section{Female donors}

Data for female donors who reported in RBTCs to donate blood/blood components, broken down into years is presented in Table 9. Countrywide, the highest number of women who reported for donation in the period 2013-2017 ranged from 8.73\% (in 2013) to $9.28 \%$ (in 2015) as compared to the total population of women who reported in RBTCs during the whole study period. The lowest number 
Table 4. Characteristics of the whole donor population who reported for donation of blood/blood components in 2005-2017 broken down into RBTCs

\begin{tabular}{|c|c|c|c|c|c|c|c|}
\hline Variable & RBTC & Average & Median & Total & Min & Max & $\%$ total \\
\hline daw_zgl_krew & Bialystok & 31684 & 32464 & 411886 & 21490 & 36510 & $4.74 \%$ \\
\hline daw_zgl_krew & Bydgoszcz & 39090 & 40343 & 508173 & 31375 & 41564 & $5.85 \%$ \\
\hline daw_zgl_krew & Gdansk & 33637 & 35597 & 437287 & 25883 & 36757 & $5.03 \%$ \\
\hline daw_zgl_krew & Kalisz & 21460 & 21544 & 278977 & 17006 & 24022 & $3.21 \%$ \\
\hline daw_zgl_krew & Katowice & 57603 & 60164 & 748841 & 47652 & 63763 & $8.62 \%$ \\
\hline daw_zgl_krew & Kielce & 19548 & 19553 & 254123 & 17346 & 21860 & $2.92 \%$ \\
\hline daw_zgl_krew & Krakow & 50081 & 53558 & 651057 & 37428 & 57878 & $7.49 \%$ \\
\hline daw_zgl_krew & Lublin & 33869 & 33601 & 440297 & 31047 & 39170 & $5.07 \%$ \\
\hline daw_zgl_krew & Lodz & 41970 & 43868 & 545604 & 32986 & 46392 & $6.28 \%$ \\
\hline daw_zgl_krew & Olsztyn & 24445 & 24577 & 317780 & 19799 & 26661 & $3.66 \%$ \\
\hline daw_zgl_krew & Opole & 16666 & 16038 & 216664 & 11898 & 20342 & $2.49 \%$ \\
\hline daw_zgl_krew & Poznan & 54007 & 56958 & 702087 & 38883 & 58916 & $8.08 \%$ \\
\hline daw_zgl_krew & Raciborz & 18200 & 18175 & 236603 & 13962 & 22396 & $2.72 \%$ \\
\hline daw_zgl_krew & Radom & 13223 & 13456 & 171902 & 10844 & 14504 & $1.98 \%$ \\
\hline daw_zgl_krew & Rzeszow & 26628 & 26046 & 346165 & 19317 & 35838 & $3.98 \%$ \\
\hline daw_zgl_krew & Slupsk & 12004 & 12573 & 156051 & 8365 & 13897 & $1.80 \%$ \\
\hline daw_zgl_krew & Szczecin & 25665 & 25932 & 333639 & 22522 & 28930 & $3.84 \%$ \\
\hline daw_zgl_krew & Walbrzych & 15436 & 15117 & 200674 & 14485 & 16875 & $2.31 \%$ \\
\hline daw_zgl_krew & Warszawa & 73159 & 74451 & 951068 & 63944 & 76177 & $10.94 \%$ \\
\hline daw_zgl_krew & Wroclaw & 42797 & 44219 & 556357 & 31067 & 47321 & $6.40 \%$ \\
\hline daw_zgl_krew & Zielona Gora & 17414 & 17970 & 226376 & 12537 & 19895 & $2.60 \%$ \\
\hline Total & & & & 8691611 & & & $100 \%$ \\
\hline
\end{tabular}

daw_zgl_krew — total number of donors

Table 5. Characteristics of voluntary non-remunerated donors who reported at RBTCs to donate blood/blood components broken down into years

\begin{tabular}{lccccccc}
\hline Variable & Year & Average & Median & Total & Min & Max & $\%$ total \\
\hline daw_zgl_krew_h & 2005 & 23645 & 21458 & 496538 & 8342 & 53348 & $6.30 \%$ \\
daw_zgl_krew_h & 2006 & 24520 & 22816 & 514922 & 9505 & 55084 & $6.53 \%$ \\
daw_zgl_krew_h & 2007 & 25950 & 23490 & 544960 & 10681 & 55482 & $6.91 \%$ \\
daw_zgl_krew_h & 2008 & 27526 & 26616 & 578053 & 11105 & 55684 & $7.33 \%$ \\
daw_zgl_krew_h & 2009 & 28870 & 26055 & 606273 & 10569 & 57923 & $7.69 \%$ \\
daw_zgl_krew_h & 2010 & 29612 & 25910 & 621847 & 11090 & 60487 & $7.89 \%$ \\
daw_zgl_krew_h & 2011 & 30735 & 26039 & 645435 & 11943 & 62932 & $8.19 \%$ \\
daw_zgl_krew_h & 2012 & 30832 & 26903 & 647479 & 12021 & 61772 & $8.21 \%$ \\
daw_zgl_krew_h & 2013 & 30036 & 27417 & 630762 & 12541 & 62539 & $8.00 \%$ \\
daw_zgl_krew_h & 2014 & 30628 & 28900 & 643180 & 11829 & 64172 & $8.16 \%$ \\
daw_zgl_krew_h & 2015 & 31885 & 29619 & 669581 & 12897 & 66000 & $8.49 \%$ \\
daw_zgl_krew_h & 2016 & 30868 & 27930 & 648235 & 11599 & 59928 & $8.22 \%$ \\
daw_zgl_krew_h & 2017 & 30381 & 27485 & 638001 & 12226 & 60669 & $8.09 \%$ \\
Total & & & 7885266 & & & $100 \%$ \\
\hline
\end{tabular}

daw_zgl_krew_h - total number of voluntary non-remunerated donors 
Table 6. Characteristics of voluntary non-remunerated-donor population who reported for donation of blood/ /blood components in the years 2005-2017, broken down into RBTCs

\begin{tabular}{|c|c|c|c|c|c|c|c|}
\hline Variable & RBTC & Average & Median & Total & Min & Max & $\%$ total \\
\hline daw_zgl_krew_h & Bialystok & 31402 & 32034 & 408232 & 21458 & 36510 & $5.18 \%$ \\
\hline daw_zgl_krew_h & Bydgoszcz & 34507 & 35001 & 448586 & 28525 & 38418 & $5.69 \%$ \\
\hline daw_zgl_krew_h & Gdansk & 30031 & 31818 & 390401 & 23490 & 33732 & $4.95 \%$ \\
\hline daw_zgl_krew_h & Kalisz & 20895 & 20930 & 271630 & 16778 & 23837 & $3.44 \%$ \\
\hline daw_zgl_krew_h & Katowice & 56261 & 58827 & 731392 & 46417 & 62985 & $9.28 \%$ \\
\hline daw_zgl_krew_h & Kielce & 15710 & 15685 & 204226 & 14362 & 18480 & $2.59 \%$ \\
\hline daw_zgl_krew_h & Krakow & 49754 & 53451 & 646802 & 36798 & 57733 & $8.20 \%$ \\
\hline daw_zgl_krew_h & Lublin & 30042 & 29619 & 390551 & 27232 & 34276 & $4.95 \%$ \\
\hline daw_zgl_krew_h & Lodz & 30476 & 31054 & 396190 & 26546 & 34848 & $5.02 \%$ \\
\hline daw_zgl_krew_h & Olsztyn & 24323 & 24568 & 316200 & 19788 & 26656 & $4.01 \%$ \\
\hline daw_zgl_krew_h & Opole & 15897 & 15542 & 206656 & 11767 & 18638 & $2.62 \%$ \\
\hline daw_zgl_krew_h & Poznan & 43533 & 46006 & 565934 & 31068 & 50324 & $7.18 \%$ \\
\hline daw_zgl_krew_h & Raciborz & 17978 & 18056 & 233713 & 13933 & 21624 & $2.96 \%$ \\
\hline daw_zgl_krew_h & Radom & 11702 & 11599 & 152123 & 10407 & 12937 & $1.93 \%$ \\
\hline daw_zgl_krew_h & Rzeszow & 26601 & 26039 & 345818 & 19310 & 35691 & $4.39 \%$ \\
\hline daw_zgl_krew_h & Slupsk & 11683 & 12144 & 151885 & 8342 & 13661 & $1.93 \%$ \\
\hline daw_zgl_krew_h & Szczecin & 25634 & 25910 & 333237 & 22499 & 28919 & $4.23 \%$ \\
\hline daw_zgl_krew_h & Walbrzych & 15279 & 14968 & 198621 & 14470 & 16460 & $2.52 \%$ \\
\hline daw_zgl_krew_h & Warszawa & 59311 & 59928 & 771038 & 53348 & 66000 & $9.78 \%$ \\
\hline daw_zgl_krew_h & Wroclaw & 38870 & 40995 & 505304 & 27389 & 42804 & $6.41 \%$ \\
\hline daw_zgl_krew_h & Zielona Gora & 16671 & 17372 & 216727 & 12384 & 19164 & $2.75 \%$ \\
\hline Total & & & & 7885266 & & & $100 \%$ \\
\hline
\end{tabular}

daw_zgl_krew_h - total number of voluntary non-remunerated donors

(958) was reported in Slupsk, in 2005, while the highest (26 300) in Warsaw, in 2015 (Table 10).

\section{Male donors}

Countrywide, the highest number of men reported for donation in the period 2008-2012, from $7.89 \%$ (in 2011) to $8.07 \%$ (in 2009) as compared to the total population of men who reported in RBTCs to donate blood/blood components during the whole study period (Table 11). Like with female donors, the lowest number (7407) was recorded in 2005, in RBTC in Slupsk, while the highest (54 792) in 2008 in RBTC in Warsaw (Table 12).

Table 13 compares the number of men and women who reported in RBTCs to donate blood/ /blood components in the period 2005-2017. The highest percentage of men was recorded in 2005 (77.99\%), while the highest percentage of women in 2016 (32.89\%.) However, the proportions between male and female donors varied during the study period. In 2005 , the men to women ratio was approximately $8: 2$, while in 2017 it was $7: 3$. The difference between the highest and lowest percentage in each group was about $11 \%$.

\section{Comparison of male and female populations}

Figure 5 and Figure 6 are a comparison between the number of women and men who reported in RBTCs in the 2005-2017 period with the intention of donating blood/blood components. According to available data, the male population was significantly larger than the female one throughout the whole study period $-70.75 \%$ and $29.25 \%$, respectively. The trend lines set out in Figure 6 indicate a growing tendency for both the male and female population, but the trend line for women is larger. The diagram demonstrates a mean value line for both male and female populations. According to the presented data, in 2008-2013 and 2015 the male population which reported at RBTCs was higher than the national average, while in 2014 and 2016 it approximated the average, and in 2017 it fell below the average value. The number of women who were willing to donate exceeded the average 
Table 7. Characteristics of responders to donation appeal who reported at RBTCs to donate blood/blood components in the period 2005-2017, broken down into years

\begin{tabular}{lccccccc}
\hline Variable & Year & Average & Median & Total & Min & Max & $\%$ total \\
\hline daw_zgl_krew_r & 2005 & 1973 & 499 & 35514 & 0 & 10149 & $4.56 \%$ \\
daw_zgl_krew_r & 2006 & 2626 & 1135 & 49898 & 0 & 11362 & $6.41 \%$ \\
daw_zgl_krew_r & 2007 & 3875 & 1314 & 73627 & 0 & 18565 & $9.45 \%$ \\
daw_zgl_krew_r & 2008 & 3974 & 1543 & 79470 & 0 & 19872 & $10.20 \%$ \\
daw_zgl_krew_r & 2009 & 3872 & 1414 & 77435 & 0 & 15499 & $9.94 \%$ \\
daw_zgl_krew_r & 2010 & 3217 & 1108 & 64335 & 0 & 13396 & $8.26 \%$ \\
daw_zgl_krew_r & 2011 & 2597 & 770 & 54547 & 0 & 11500 & $7.00 \%$ \\
daw_zgl_krew_r & 2012 & 2784 & 745 & 58468 & 0 & 12977 & $7.51 \%$ \\
daw_zgl_krew_r & 2013 & 3528 & 991 & 74084 & 0 & 17143 & $9.51 \%$ \\
daw_zgl_krew_r & 2014 & 2670 & 1715 & 56067 & 0 & 12752 & $7.20 \%$ \\
daw_zgl_krew_r & 2015 & 2278 & 416 & 47837 & 0 & 12875 & $6.14 \%$ \\
daw_zgl_krew_r & 2016 & 2650 & 557 & 55647 & 0 & 16883 & $7.15 \%$ \\
daw_zgl_krew_r & 2017 & 2470 & 679 & 51874 & 0 & 15798 & $6.66 \%$ \\
Total & & & 778803 & & $100 \%$ \\
\hline
\end{tabular}

daw_zgl_krew_r - responders to donation appeal

Table 8. Characteristics of responders to donation appeal who reported to donate blood/blood components in the period 2005-2017, broken down into RBTCs

\begin{tabular}{|c|c|c|c|c|c|c|c|}
\hline Variable & RBTC & Average & Median & Total & Mini & Max & $\%$ total \\
\hline daw_zgl_krew_r & Bialystok & 313 & 0 & 3125 & 0 & 2517 & $0.40 \%$ \\
\hline daw_zgl_krew_r & Bydgoszcz & 4429 & 4252 & 57582 & 1661 & 7610 & $7.39 \%$ \\
\hline daw_zgl_krew_r & Gdansk & 3566 & 3556 & 46361 & 1715 & 6138 & $5.95 \%$ \\
\hline daw_zgl_krew_r & Kalisz & 538 & 533 & 6997 & 146 & 978 & $0.90 \%$ \\
\hline daw_zgl_krew_r & Katowice & 983 & 792 & 12783 & 285 & 2277 & $1.64 \%$ \\
\hline daw_zgl_krew_r & Kielce & 3830 & 3855 & 49788 & 2583 & 6108 & $6.39 \%$ \\
\hline daw_zgl_krew_r & Krakow & 87 & 51 & 1131 & 0 & 246 & $0.15 \%$ \\
\hline daw_zgl_krew_r & Lublin & 3691 & 3495 & 47980 & 1489 & 6279 & $6.16 \%$ \\
\hline daw_zgl_krew_r & Lodz & 11155 & 11488 & 145018 & 3639 & 16883 & $18.62 \%$ \\
\hline daw_zgl_krew_r & Olsztyn & 135 & 0 & 1485 & 0 & 714 & $0.19 \%$ \\
\hline daw_zgl_krew_r & Opole & 651 & 416 & 8464 & 0 & 1574 & $1.09 \%$ \\
\hline daw_zgl_krew_r & Poznan & 10364 & 10155 & 134732 & 7196 & 15229 & $17.30 \%$ \\
\hline daw_zgl_krew_r & Raciborz & 288 & 239 & 3451 & 14 & 874 & $0.44 \%$ \\
\hline daw_zgl_krew_r & Radom & 1490 & 1349 & 19369 & 411 & 2497 & $2.49 \%$ \\
\hline daw_zgl_krew_r & Rzeszow & 3 & 0 & 27 & 0 & 19 & $0.00 \%$ \\
\hline daw_zgl_krew_r & Slupsk & 318 & 331 & 4131 & 0 & 655 & $0.53 \%$ \\
\hline daw_zgl_krew_r & Szczecin & 18 & 14 & 231 & 2 & 72 & $0.03 \%$ \\
\hline daw_zgl_krew_r & Walbrzych & 140 & 128 & 1819 & 0 & 474 & $0.23 \%$ \\
\hline daw_zgl_krew_r & Warsaw & 13566 & 12893 & 176360 & 10079 & 19872 & $22.65 \%$ \\
\hline daw_zgl_krew_r & Wroclaw & 3766 & 3810 & 48954 & 1756 & 4993 & $6.29 \%$ \\
\hline daw_zgl_krew_r & Zielona Gora & 693 & 587 & 9015 & 246 & 1379 & $1.16 \%$ \\
\hline Total & & & & 778803 & & & $100 \%$ \\
\hline
\end{tabular}

daw_zgl_krew_r - responders to donation appeal 


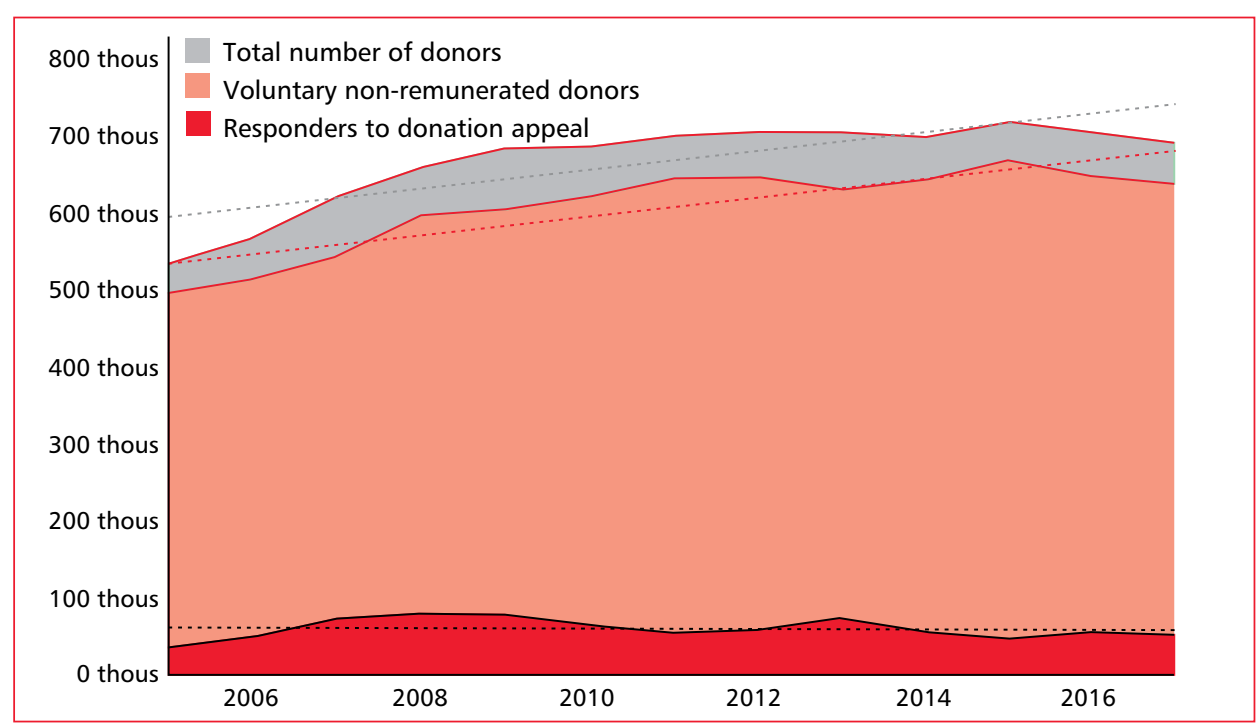

Figure 3. Total number of donors who reported at RBTCs to donate blood/blood components in 2005-2017; including non-remunerated donors and responders to donation appeal

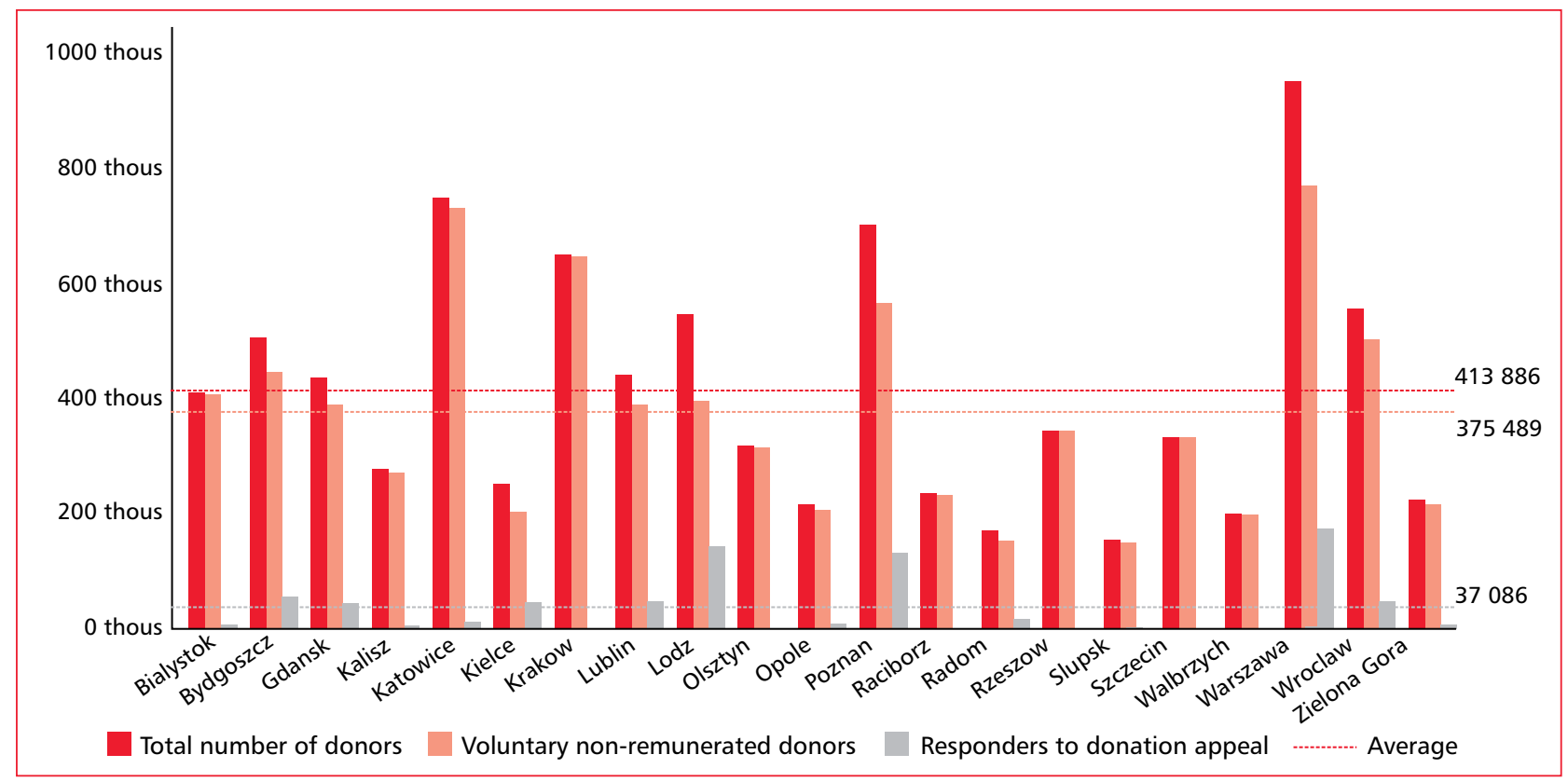

Figure 4. Number of donors who reported at RBTCs to donate blood vs number of non-remunerated donors (total for 2005-2017)

value in 2010 and this trend was observed until the end of the study period, i.e. until 2017.

Comparison of the number of women and men broken down into RBTCs is presented in Figure 7.

\section{Donor age}

For the purpose of analysis, data with regard to donor age was divided into two groups: data for 2005-2010 (Group 1) and data for 2011-2017 (Group 2). Otherwise, a reliable comparison of data (i.e. for the entire study period) would not be possible due to differences in determined agecategories. In the period 2005-2010, the age of donors who reported at RBTCs to donate blood/blood components was broken down into the following categories: $18-30,31-45,46-65$ and one group of donors below 18 and above 65. In 2011-2017 how- 
Table 9. Number of women who reported at RBTCs to donate blood/blood components broken down into years

\begin{tabular}{lccccccc}
\hline Variable & Year & Average & Median & Total & Min & Max & $\%$ total \\
\hline daw_zgl_krew_K & 2005 & 5601 & 4429 & 117616 & 958 & 14788 & $4.63 \%$ \\
daw_zgl_krew_K & 2006 & 6291 & 4316 & 132109 & 1372 & 16759 & $5.20 \%$ \\
daw_zgl_krew_K & 2007 & 7432 & 5562 & 156069 & 2173 & 20576 & $6.14 \%$ \\
daw_zgl_krew_K & 2008 & 8213 & 6035 & 172481 & 2466 & 21096 & $6.78 \%$ \\
daw_zgl_krew_K & 2009 & 8976 & 6686 & 188498 & 2724 & 21064 & $7.41 \%$ \\
daw_zgl_krew_K & 2010 & 9641 & 6691 & 202457 & 3483 & 22201 & $7.96 \%$ \\
daw_zgl_krew_K & 2011 & 10322 & 7402 & 216762 & 3561 & 23116 & $8.53 \%$ \\
daw_zgl_krew_K & 2012 & 10345 & 7472 & 217245 & 3556 & 23895 & $8.54 \%$ \\
daw_zgl_krew_K & 2013 & 10573 & 8131 & 222035 & 3676 & 24398 & $8.73 \%$ \\
daw_zgl_krew_K & 2014 & 10825 & 8575 & 227319 & 3939 & 25438 & $8.94 \%$ \\
daw_zgl_krew_K & 2015 & 11234 & 9780 & 235913 & 4138 & 26300 & $9.28 \%$ \\
daw_zgl_krew_K & 2016 & 11065 & 9660 & 232362 & 3818 & 24834 & $9.14 \%$ \\
daw_zgl_krew_K & 2017 & 10560 & 9417 & 221755 & 3752 & 23877 & $8.72 \%$ \\
Total & & & 2542621 & & & $100 \%$ \\
\hline
\end{tabular}

daw_zgl_krew_K - total number of female donors

Table 10. Number of women who reported for donation of blood/blood components in the period 2005-2017 broken down into RBTCs

\begin{tabular}{|c|c|c|c|c|c|c|c|}
\hline Variable & RBTC & Average & Median & Total & Minimum & Maximum & $\%$ total \\
\hline daw_zgl_krew_K & Bialystok & 9804 & 10857 & 127458 & 5562 & 13265 & $5.01 \%$ \\
\hline daw_zgl_krew_K & Bydgoszcz & 12316 & 13668 & 160108 & 6829 & 14598 & $6.30 \%$ \\
\hline daw_zgl_krew_K & Gdansk & 9968 & 11185 & 129590 & 5359 & 11883 & $5.10 \%$ \\
\hline daw_zgl_krew_K & Kalisz & 6188 & 6343 & 80438 & 3712 & 7669 & $3.16 \%$ \\
\hline daw_zgl_krew_K & Katowice & 15288 & 16006 & 198747 & 11021 & 18265 & $7.82 \%$ \\
\hline daw_zgl_krew_K & Kielce & 5486 & 5461 & 71324 & 3759 & 7739 & $2.81 \%$ \\
\hline daw_zgl_krew_K & Krakow & 15473 & 18029 & 201155 & 8888 & 19430 & $7.91 \%$ \\
\hline daw_zgl_krew_K & Lublin & 9638 & 9780 & 125288 & 7203 & 10967 & $4.93 \%$ \\
\hline daw_zgl_krew_K & Lodz & 13473 & 14487 & 175155 & 8282 & 16795 & $6.89 \%$ \\
\hline daw_zgl_krew_K & Olsztyn & 6722 & 7373 & 87388 & 3061 & 8628 & $3.44 \%$ \\
\hline daw_zgl_krew_K & Opole & 5095 & 4857 & 66231 & 3429 & 6185 & $2.60 \%$ \\
\hline daw_zgl_krew_K & Poznan & 16535 & 18095 & 214952 & 8449 & 19733 & $8.45 \%$ \\
\hline daw_zgl_krew_K & Raciborz & 4185 & 4119 & 54406 & 2863 & 5669 & $2.14 \%$ \\
\hline daw_zgl_krew_K & Radom & 3923 & 4371 & 51005 & 2433 & 4785 & $2.01 \%$ \\
\hline daw_zgl_krew_K & Rzeszow & 6659 & 6695 & 86573 & 3483 & 10406 & $3.40 \%$ \\
\hline daw_zgl_krew_K & Slupsk & 3065 & 3556 & 39840 & 958 & 4143 & $1.57 \%$ \\
\hline daw_zgl_krew_K & Szczecin & 6539 & 6799 & 85011 & 2954 & 9156 & $3.34 \%$ \\
\hline daw_zgl_krew_K & Walbrzych & 4597 & 4965 & 59767 & 2842 & 5371 & $2.35 \%$ \\
\hline daw_zgl_krew_K & Warsaw & 22180 & 23116 & 288342 & 14788 & 26300 & $11.34 \%$ \\
\hline daw_zgl_krew_K & Wroclaw & 13941 & 14691 & 181233 & 8172 & 15867 & $7.13 \%$ \\
\hline daw_zgl_krew_K & Zielona Gora & 4508 & 4836 & 58610 & 1456 & 6231 & $2.31 \%$ \\
\hline Total & & & & 2542621 & & & $100 \%$ \\
\hline
\end{tabular}

daw_zgl_krew_K - total number of female donors 
Table 11. Number of men who reported at RBTCs to donate blood/blood components broken down into years

\begin{tabular}{lccccccc}
\hline Variable & Year & Average & Median & Total & Min & Max & $\%$ total \\
\hline daw_zgl_krew_M & 2005 & 19844 & 16738 & 416726 & 7407 & 49156 & $6.78 \%$ \\
daw_zgl_krew_M & 2006 & 20745 & 18472 & 435651 & 8468 & 50129 & $7.08 \%$ \\
daw_zgl_krew_M & 2007 & 22204 & 20419 & 466288 & 9210 & 53875 & $7.58 \%$ \\
daw_zgl_krew_M & 2008 & 23218 & 20626 & 487575 & 10146 & 54792 & $7.93 \%$ \\
daw_zgl_krew_M & 2009 & 23639 & 19997 & 496410 & 8191 & 52749 & $8.07 \%$ \\
daw_zgl_krew_M & 2010 & 23134 & 19241 & 485815 & 8932 & 51963 & $7.90 \%$ \\
daw_zgl_krew_M & 2011 & 23101 & 19351 & 485120 & 8575 & 51594 & $7.89 \%$ \\
daw_zgl_krew_M & 2012 & 23349 & 19964 & 490333 & 8694 & 51184 & $7.97 \%$ \\
daw_zgl_krew_M & 2013 & 23058 & 20321 & 484211 & 9076 & 50621 & $7.87 \%$ \\
daw_zgl_krew_M & 2014 & 22540 & 21073 & 473347 & 8952 & 50213 & $7.70 \%$ \\
daw_zgl_krew_M & 2015 & 22999 & 21999 & 482974 & 9268 & 49877 & $7.85 \%$ \\
daw_zgl_krew_M & 2016 & 22577 & 21768 & 474114 & 8573 & 48060 & $7.71 \%$ \\
daw_zgl_krew_M & 2017 & 22401 & 21630 & 470426 & 8790 & 48513 & $7.65 \%$ \\
Total & & & & 6148990 & & & $100 \%$ \\
\hline
\end{tabular}

daw_zgl_krew_M - total number of male donors

ever, the age ranges for donors were determined as follows: below 18, 18-24, 25-44, 45-65 and above 65 . The change referred to the population of both women and men (Table 14).

\section{Group 1}

According to available data, in the period 2005-2010 a total of 3757695 donors reported in RBTCs to donate blood/blood components; 3754731 were donors of 18-65 (i.e. age-range eligible for blood donation). A separate group were donors under 18 and over 65 (daw_zgł_krew_m18_w65_K+M) eligible for blood/blood component donation only in special circumstances. The latter was by far the least numerous group - only 2964 donors reported during the whole study period. Accordingly, further analyses were performed for the group of donors aged $18-65$ and the group "under 18 and above 65" was disregarded.

Among donors who reported at RBTCs in 2005-2010 and could routinely donate blood, by far the most numerous group were donors aged $18-30$ ( $>60 \%$ of the total number of donors); on average -18002 donors per RBTC per year. The least numerous category were donors aged 46-65 (daw_zgł_krew_4665_K+M) - less than 500000 (slightly above 13\%). Donors aged 31-45 (daw zgt krew_3145_K+M) constituted a group of $99 \overline{1} 81 \overline{3}$ (over $26 \%$ of the total donor population) (Table 15).

Tables 16, 17 and 18 present the basic numerical data which describe the donor population of various age categories.
According to Table 16, in the $18-30$ agecategory, the highest number of donors (423 687) reported for donation in 2010 ( $>18 \%$ of the overall donor number in this age-category). The lowest number (6019) was recorded in 2005, in Slupsk; the highest (41 290) in 2010, in Warsaw (Table 17).

According to Table 18, most donors aged 31-45 reported for blood/blood component donation in 2009 (186 637 i.e. > 18\% of the total donor population in this age-category). The lowest number (1536) was recorded in 2005; the highest (23 956) in 2009. The number of donors aged 31-45 who reported to RBTCs in the period 2005-2010 is presented in Table 19.

The least numerous was the $46-65$ age-group. Most donors (86 885) reported for donation in 2008 ( $>17 \%$ of the total number of donors in this age - category). The lowest number (808) was recorded in 2005 at the RBTC in Slupsk; the highest (11 739) in 2007 at the RBTC in Warsaw (Table 20, Table 21).

Summary of data on specific age categories is presented in the Figure 8 . The trend lines for each variable indicate a clear upward trend for donorage $18-30$ and $31-45$, and no distinctive trend for 46-65. It can therefore be presumed that if the structure of the collected data had remained unchanged, a further increase of donor population in the first two age-groups would have been observed and the population of the 46-65 group would have been relatively constant (app. 80 thousand donors per year). 
Table 12. Number of men who reported for donation of blood/blood components in the years 2005-2017 broken down into RBTCs

\begin{tabular}{|c|c|c|c|c|c|c|c|}
\hline Variable & RBTC & Average & Median & Total & Minimum & Maximum & $\%$ total \\
\hline daw_zgl_krew_M & Bialystok & 21879 & 22312 & 284428 & 15777 & 25382 & $4.63 \%$ \\
\hline daw_zgl_krew_M & Bydgoszcz & 26774 & 26675 & 348065 & 24546 & 29116 & $5.66 \%$ \\
\hline daw_zgl_krew_M & Gdansk & 23669 & 23935 & 307697 & 20524 & 25434 & $5.00 \%$ \\
\hline daw_zgl_krew_M & Kalisz & 15272 & 15339 & 198539 & 13294 & 16432 & $3.23 \%$ \\
\hline daw_zgl_krew_M & Katowice & 42315 & 43812 & 550094 & 36631 & 45937 & $8.95 \%$ \\
\hline daw_zgl_krew_M & Kielce & 14061 & 14030 & 182799 & 13571 & 14750 & $2.97 \%$ \\
\hline daw_zgl_krew_M & Krakow & 34608 & 35529 & 449902 & 28540 & 38773 & $7.32 \%$ \\
\hline daw_zgl_krew_M & Lublin & 24231 & 23758 & 315009 & 21630 & 28203 & $5.12 \%$ \\
\hline daw_zgl_krew_M & Lodz & 28496 & 28754 & 370449 & 24704 & 30463 & $6.02 \%$ \\
\hline daw_zgl_krew_M & Olsztyn & 17722 & 17175 & 230392 & 16136 & 20626 & $3.75 \%$ \\
\hline daw_zgl_krew_M & Opole & 11572 & 11140 & 150433 & 7469 & 14192 & $2.45 \%$ \\
\hline daw_zgl_krew_M & Poznan & 37472 & 38412 & 487135 & 30434 & 41416 & $7.92 \%$ \\
\hline daw_zgl_krew_M & Raciborz & 14015 & 14037 & 182197 & 11099 & 16727 & $2.96 \%$ \\
\hline daw_zgl_krew_M & Radom & 9300 & 9338 & 120897 & 8411 & 10146 & $1.97 \%$ \\
\hline daw_zgl_krew_M & Rzeszow & 19969 & 19964 & 259592 & 15834 & 25432 & $4.22 \%$ \\
\hline daw_zgl_krew_M & Slupsk & 8939 & 8790 & 116211 & 7407 & 10469 & $1.89 \%$ \\
\hline daw_zgl_krew_M & Szczecin & 19125 & 19238 & 248628 & 18310 & 19774 & $4.04 \%$ \\
\hline daw_zgl_krew_M & Walbrzych & 10839 & 10759 & 140907 & 9702 & 11937 & $2.29 \%$ \\
\hline daw_zgl_krew_M & Warsaw & 50979 & 50621 & 662726 & 48060 & 54792 & $10.78 \%$ \\
\hline daw_zgl_krew_M & Wroclaw & 28856 & 29501 & 375124 & 22895 & 32217 & $6.10 \%$ \\
\hline daw_zgl_krew_M & Zielona Gora & 12905 & 12591 & 167766 & 11081 & 15928 & $2.73 \%$ \\
\hline Total & & & & 6148990 & & & $100 \%$ \\
\hline
\end{tabular}

daw_zgl_krew_M - total number of male donors

Table 13. Numbers of men and women who reported to donate blood/blood components in 2005-2017 vs the total number of donors

\begin{tabular}{lccccc}
\hline Year & daw_zgl_krew_ & daw_zgl_krew_M & daw_zgl_krew_K & \% M & $\%$ K \\
\hline 2005 & 534342 & 416726 & 117616 & $77.99 \%$ & $22.01 \%$ \\
2006 & 567760 & 435651 & 132109 & $76.73 \%$ & $23.27 \%$ \\
2007 & 622357 & 466288 & 156069 & $74.92 \%$ & $25.08 \%$ \\
2008 & 660056 & 487575 & 172481 & $73.87 \%$ & $26.13 \%$ \\
2009 & 684908 & 496410 & 188498 & $72.48 \%$ & $27.52 \%$ \\
2010 & 688272 & 485815 & 202457 & $70.58 \%$ & $29.42 \%$ \\
2011 & 701882 & 485120 & 216762 & $69.12 \%$ & $30.88 \%$ \\
2012 & 707578 & 490333 & 217245 & $69.30 \%$ & $30.70 \%$ \\
2013 & 706246 & 484211 & 222035 & $68.56 \%$ & $31.44 \%$ \\
2014 & 700666 & 473347 & 227319 & $67.56 \%$ & $32.44 \%$ \\
2015 & 718887 & 482974 & 235913 & $67.18 \%$ & $32.82 \%$ \\
2016 & 706476 & 474114 & 232362 & $67.11 \%$ & $32.89 \%$ \\
2017 & 692181 & 470426 & 221755 & $67.96 \%$ & $32.04 \%$ \\
Total & 8691611 & 6148990 & 2542621 & & \\
\hline
\end{tabular}

daw_zgl_krew — total number of donors; daw_zgl_krew_M - total number of male donors; daw_zgl_krew_K — total number of female donors; \% $M$ - \% male donors; \% $\mathrm{K}-\%$ female donors 


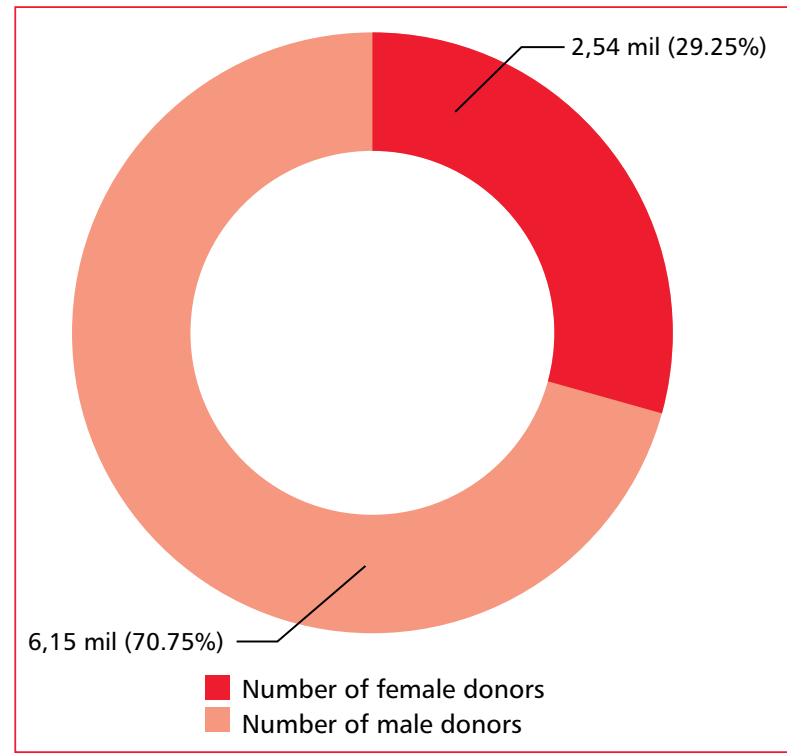

Figure 5. Percentage of women and men in the general donor population (2005-2017)

\section{Female donors}

The most numerous group were women aged 18-30, the least numerous were women aged 46-65 (Figure 9). The highest number of women aged 18-30 (143 771) was reported in 2010 (> 21\% of the donor population in this age-category). The lowest number was recorded in 2005 in RBTC in
Slupsk (787), the highest in 2010 in the RBTC in Warsaw (14 611) (Table 22, Table 23).

During the study period a total of 203392 women aged 31-45 reported at RBTCs to donate blood/blood components (Table 24). Most women (43 524-21.04\%) reported in 2010 in RBTC in Warsaw (Table 24). The minimum number (132) was recorded in 2005 for RBTC in Slupsk, the maximum number (5925) was recorded in 2009 for RBTC in Warsaw (Table 24, Table 25).

The highest number of women aged 46-65 reported in RBTCs in 2008; it was estimated at 16066 , almost $19 \%$ of the overall women population of this age who volunteered to donate blood/ /blood components (Table 26). The highest value was recorded in $2007-2457$ women, and the lowest in $2005-39$ women who, like in the other age categories, reported in RBTC in Warsaw and RBTC in Slupsk respectively (Table 27).

Summary of data referring to specific age categories of women who reported in RBTCs in the period 2005-2010 with the intention of donating blood/blood components is presented in Figure 9. As for the general donor population (Figure 8), the trend line for each variable indicates a clear upward tendency for 18-30 and 31-45, and no distinctive tendency for 46-65. It can therefore be assumed that, if the structure of the collected data had remained unchanged, a further increase in the population of women in the first two age groups

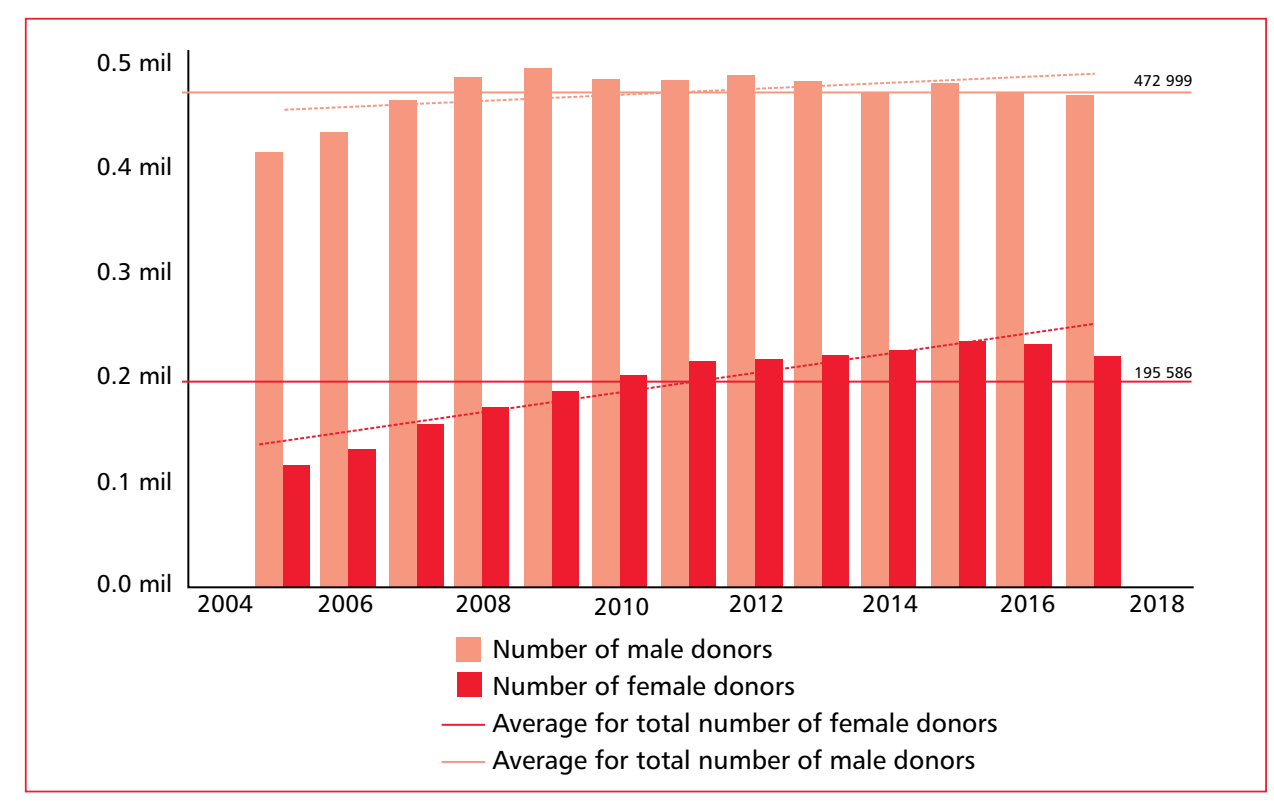

Figure 6. Comparison of the number of women and men who reported in RBTCs to donate blood/blood components (2005-2017) 


\begin{tabular}{|r|r|r|}
\hline Warszawa & 288342663726 \\
Poznan & 214952487135 \\
Krakow & 201155449902 \\
Katowice & 198747550094 \\
Wroclaw & 181233375124 \\
Lodz & 175155370449 \\
Bydgoszcz & 160108348065 \\
Gdansk & 129590 & 307697 \\
Bialystok & 127458 & 284428 \\
Lublin & 125288 & 315009 \\
Olsztyn & 87388 & 230392 \\
Rzeszow & 86573 & 259592 \\
Szczecin & 85011 & 248628 \\
Kalisz & 80438 & 198539 \\
Kielce & 71324 & 182799 \\
Opole & 66231 & 150433 \\
Walbrzych & 59767 & 140907 \\
Zielona Gora & 58610 & 167766 \\
Raciborz & 54406 & 182197 \\
Radom & 51005 & 120897 \\
Slupsk & 39840 & 116211 \\
\hline
\end{tabular}

Figure 7. Number of women and men who reported for donation of blood/blood components in 2005-2017 broken down into RBTCs

Table 14. Age categories in group 1 and group 2

\begin{tabular}{|c|c|c|c|c|c|c|c|c|c|}
\hline \multirow[t]{2}{*}{ Years } & \multicolumn{9}{|c|}{ Age - category } \\
\hline & $18-30$ & $31-45$ & $46-65$ & $<18 \mathrm{i}>65$ & $<18$ & $18-24$ & $25-44$ & $45-65$ & $>65$ \\
\hline 2005-2010 (group 1) & $x$ & $x$ & $x$ & $x$ & & & & & \\
\hline 2011-2017 (group 2) & & & & & $x$ & $x$ & $x$ & $x$ & $x$ \\
\hline
\end{tabular}

Table 15. Characteristics of donors who reported at RBTCs to donate blood/blood components in 2005-2010, broken down into age-categories

\begin{tabular}{lcccccc}
\hline Variable & Average & Median & Total & Min & Max & $\%$ total \\
\hline daw_zgł_krew_1830_K+M & 18002 & 16270 & 2268193 & 6019 & 41290 & $60.36 \%$ \\
daw_zgł_krew_3145_K+M & 7872 & 5998 & 991813 & 1536 & 23956 & $26.39 \%$ \\
daw_zgł_krew_4665_K+M & 3926 & 3028 & 494725 & 808 & 11739 & $13.17 \%$ \\
daw_zgł_krew_m18_w65_K+M & 24 & 10 & 2964 & 0 & 145 & $0.08 \%$ \\
Total & & & $\mathbf{3 7 5 7 6 9 5}$ & & $100 \%$ \\
\hline
\end{tabular}

daw_zgl_krew_1830_K+M - total number of donors (male + female) in the 18-30 age category daw zgl krew $3145 \mathrm{~K}+\mathrm{M}$ - total number of donors (male + female) in the 31-45 age category

daw zgl krew 4665 $\mathrm{K}+\mathrm{M}$ - total number of donors (male +female) in the 46-65 age category

daw_zgl krew_m18 w65 $\mathrm{K}+\mathrm{M}$ - total number of donors (male +female) below 18 and above 65

would have been observed and the population of the 46-65 group would have been relatively constant (app. 15 thousand donors per year).

Male donors

As for women, the most numerous was the 18-30 group and the least numerous, the group of men aged 46-65 (Figure 10); a total of 1588581 donors in the 18-30 age group reported to donate blood/blood component. In 2009, the number of men in this age category was the highest -282 794 ( $>17 \%$ of the donor population in this age category). The lowest value was recorded in 2005 (3295) at the RBTC in Opole, and the highest in 2007 (27 652) at the RBTC in Warsaw (Table 28, Table 29). 
Table 16. Characteristics of the donor population aged 18-30 broken down into years

\begin{tabular}{lccccccc}
\hline Variable & Year & Average & Median & Total & Min & Max & $\%$ total \\
\hline daw_zgł_krew_1830_K+M & 2005 & 15101 & 14567 & 317115 & 6019 & 34373 & $13.98 \%$ \\
daw_zgł_krew_1830_K+M & 2006 & 16212 & 14434 & 340459 & 7309 & 36427 & $15.01 \%$ \\
daw_zgł_krew_1830_K+M & 2007 & 17801 & 17482 & 373824 & 7696 & 40580 & $16.48 \%$ \\
daw_zgł_krew_1830_K+M & 2008 & 19010 & 16413 & 399202 & 8611 & 41042 & $17.60 \%$ \\
daw_zgł_krew_1830_K+M & 2009 & 19710 & 17332 & 413906 & 7590 & 39859 & $18.25 \%$ \\
daw_zgł_krew_1830_K+M & 2010 & 20176 & 17142 & 423687 & 8441 & 41290 & $18.68 \%$ \\
Total & & & & $\mathbf{2 2 6 8 1 9 3}$ & & & $\mathbf{1 0 0 \%}$ \\
\hline
\end{tabular}

daw_zgł_krew_1830_K+M - total number of donors (male +female) in the 18-30 age category

Table 17. Number of donors aged 18-30 who reported for donation of blood/blood components in the years 2005-2010 broken down into RBTCs

\begin{tabular}{|c|c|c|c|c|c|c|c|}
\hline Variable & RBTC & Average & Median & Total & Min & Max & $\%$ total \\
\hline daw_zgł_krew_1830_K+M & Bialystok & 17635 & 17698 & 105809 & 15371 & 20632 & $4.66 \%$ \\
\hline daw_zgł_krew_1830_K+M & Bydgoszcz & 22239 & 22613 & 133434 & 18449 & 24451 & $5.88 \%$ \\
\hline daw_zgł_krew_1830_K+M & Gdansk & 18601 & 18245 & 111606 & 14977 & 22306 & $4.92 \%$ \\
\hline daw_zgł_krew_1830_K+M & Kalisz & 11406 & 11874 & 68438 & 9580 & 12310 & $3.02 \%$ \\
\hline daw_zgł_krew_1830_K+M & Katowice & 28754 & 28139 & 172522 & 24510 & 34302 & $7.61 \%$ \\
\hline daw_zgł_krew_1830_K+M & Kielce & 10762 & 10605 & 64571 & 9782 & 11628 & $2.85 \%$ \\
\hline daw_zgł_krew_1830_K+M & Krakow & 26384 & 25923 & 158301 & 21969 & 31253 & $6.98 \%$ \\
\hline daw_zgł_krew_1830_K+M & Lublin & 24322 & 24287 & 145932 & 22407 & 26612 & $6.43 \%$ \\
\hline daw_zgł_krew_1830_K+M & Lodz & 22931 & 22199 & 137583 & 19355 & 27486 & $6.07 \%$ \\
\hline daw_zgł_krew_1830_K+M & Olsztyn & 16504 & 16730 & 99022 & 13540 & 18980 & $4.37 \%$ \\
\hline daw_zgł_krew_1830_K+M & Opole & 10450 & 10997 & 62699 & 6102 & 13457 & $2.76 \%$ \\
\hline daw_zgł_krew_1830_K+M & Poznan & 29019 & 29931 & 174113 & 22095 & 34098 & $7.68 \%$ \\
\hline daw_zgł_krew_1830_K+M & Raciborz & 9605 & 9436 & 57631 & 7292 & 12287 & $2.54 \%$ \\
\hline daw_zgł_krew_1830_K+M & Radom & 7985 & 8084 & 47910 & 6754 & 8720 & $2.11 \%$ \\
\hline daw_zgł_krew_1830_K+M & Rzeszow & 14800 & 14942 & 88801 & 13071 & 16646 & $3.92 \%$ \\
\hline daw_zgł_krew_1830_K+M & Slupsk & 8017 & 8016 & 48100 & 6019 & 9508 & $2.12 \%$ \\
\hline daw_zgł_krew_1830_K+M & Szczecin & 15285 & 15062 & 91707 & 14431 & 17142 & $4.04 \%$ \\
\hline daw_zgł_krew_1830_K+M & Walbrzych & 8733 & 8664 & 52399 & 7600 & 9998 & $2.31 \%$ \\
\hline daw_zgł_krew_1830_K+M & Warsaw & 38929 & 40220 & 233571 & 34373 & 41290 & $10.30 \%$ \\
\hline daw_zgł_krew_1830_K+M & Wroclaw & 24395 & 25165 & 146368 & 18129 & 28878 & $6.45 \%$ \\
\hline daw_zgł_krew_1830_K+M & Zielona Gora & 11279 & 11230 & 67676 & 8866 & 14180 & $2.98 \%$ \\
\hline Total & \multicolumn{6}{|c|}{2268193} & $100 \%$ \\
\hline
\end{tabular}

daw_zgł_krew_1830_K+M - total number of donors (male +female) in the 18-30 age category

In the period 2005-2010 a total of 788421 donors of the 31-45 age group reported to donate blood/blood components (Table 30). Most of them reported in $2009-144872$ in all ( $>18 \%$ of the donor population in this age category). In the same year, the highest number of donors in this age-category was recorded at RBTC in Warsaw 18031 donors. The lowest number -1404 was recorded in RBTC in Slupsk (Table 31).

In the period 2005-2010, 409690 donors aged 46-65 reported at RBTCs to donate blood/blood components. The highest number - 71013 in all 
Table 18. Characteristics of the donor population aged 31-45 broken down into years

\begin{tabular}{lccccccc}
\hline Variable & Year & Average & Median & Total & Min & Max & $\%$ total \\
\hline daw_zgł_krew_3145_K+M & 2005 & 6678 & 4867 & 140242 & 1536 & 18445 & $14.14 \%$ \\
daw_zgł_krew_3145_K+M & 2006 & 6942 & 5104 & 145776 & 1632 & 19432 & $14.70 \%$ \\
daw_zgł_krew_3145_K+M & 2007 & 7701 & 5800 & 161712 & 2060 & 22097 & $16.30 \%$ \\
daw_zgł_krew_3145_K+M & 2008 & 8262 & 5751 & 173509 & 2262 & 23137 & $17.49 \%$ \\
daw_zgł_krew_3145_K+M & 2009 & 8887 & 6126 & 186637 & 2232 & 23956 & $18.82 \%$ \\
daw_zgł_krew_3145_K+M & 2010 & 8759 & 6513 & 183937 & 2773 & 23049 & $18.55 \%$ \\
Total & & & & 991813 & & & $100 \%$ \\
\hline
\end{tabular}

daw_zgł_krew_3145_K+M - total number of donors (male +female) in the 31-45 age category

Table 19. Number of donors aged 31-45 who reported for blood/blood component donation in the years 20052010 broken down into RBTCs

\begin{tabular}{|c|c|c|c|c|c|c|c|}
\hline Variable & RBTC & Average & Median & Total & Min & Max & $\%$ total \\
\hline daw_zgł_krew_3145_K+M & Bialystok & 6974 & 7163 & 41846 & 4086 & 10639 & $4.22 \%$ \\
\hline daw_zgł_krew_3145_K+M & Bydgoszcz & 9798 & 9938 & 58786 & 8047 & 11345 & $5.93 \%$ \\
\hline daw_zgł_krew_3145_K+M & Gdansk & 8739 & 8424 & 52436 & 7345 & 10368 & $5.29 \%$ \\
\hline daw_zgł_krew_3145_K+M & Kalisz & 5501 & 5590 & 33007 & 4709 & 6094 & $3.33 \%$ \\
\hline daw_zgł_krew_3145_K+M & Katowice & 16070 & 15702 & 96422 & 14657 & 18125 & $9.72 \%$ \\
\hline daw_zgł_krew_3145_K+M & Kielce & 4711 & 4718 & 28263 & 4527 & 4867 & $2.85 \%$ \\
\hline daw_zgł_krew_3145_K+M & Krakow & 11214 & 11243 & 67282 & 10023 & 12234 & $6.78 \%$ \\
\hline daw_zgł_krew_3145_K+M & Lublin & 7690 & 7698 & 46137 & 6682 & 8617 & $4.65 \%$ \\
\hline daw_zgł_krew_3145_K+M & Lodz & 10002 & 10328 & 60011 & 8304 & 11181 & $6.05 \%$ \\
\hline daw_zgł_krew_3145_K+M & Olsztyn & 5052 & 5039 & 30310 & 4268 & 6060 & $3.06 \%$ \\
\hline daw_zgł_krew_3145_K+M & Opole & 3891 & 3862 & 23345 & 3062 & 4672 & $2.35 \%$ \\
\hline daw_zgł_krew_3145_K+M & Poznan & 14468 & 14612 & 86805 & 10883 & 17508 & $8.75 \%$ \\
\hline daw_zgł_krew_3145_K+M & Raciborz & 5589 & 5258 & 33535 & 4864 & 7036 & $3.38 \%$ \\
\hline daw_zgł_krew_3145_K+M & Radom & 2826 & 2833 & 16955 & 2531 & 3063 & $1.71 \%$ \\
\hline daw_zgł_krew_3145_K+M & Rzeszow & 4990 & 4991 & 29938 & 4162 & 5936 & $3.02 \%$ \\
\hline daw_zgł_krew_3145_K+M & Slupsk & 2083 & 2146 & 12495 & 1536 & 2773 & $1.26 \%$ \\
\hline daw_zgł_krew_3145_K+M & Szczecin & 5792 & 5776 & 34751 & 5390 & 6334 & $3.50 \%$ \\
\hline daw_zgł_krew_3145_K+M & Walbrzych & 4421 & 4522 & 26528 & 3994 & 4688 & $2.67 \%$ \\
\hline daw_zgł_krew_3145_K+M & Warsaw & 21686 & 22573 & 130116 & 18445 & 23956 & $13.12 \%$ \\
\hline daw_zgł_krew_3145_K+M & Wroclaw & 10568 & 10552 & 63409 & 7946 & 12866 & $6.39 \%$ \\
\hline daw_zgł_krew_3145_K+M & Zielona Gora & 3239 & 3171 & 19436 & 2345 & 4157 & $1.96 \%$ \\
\hline Total & & & & 991813 & & & $100 \%$ \\
\hline
\end{tabular}

daw_zgł_krew_3145_K+M - total number of donors (male + female) in the 31-45 age category

— was recorded in 2007 ( $>17 \%$ of the male donor population in this age category). In 2008 , the highest value was recorded at RBTC in Warsaw (9322 donors) and the lowest (769) in Slupsk (Table 32 and Table 33).
Summary of data referring to specific age categories of men who reported in RBTCs in the period 2005-2010 with the intention of donating blood/blood components is presented in Figure 10. As for the general donor population (Figure 8 ) and 
Table 20. Characteristics of the donor population aged 46-65 broken down into years

\begin{tabular}{lccccccc}
\hline Variable & Year & Average & Median & Total & Min & Max & $\%$ total \\
\hline daw_zgł_krew_4665_K+M & 2005 & 3641 & 2710 & 76465 & 808 & 11090 & $15.46 \%$ \\
daw_zgł_krew_4665_K+M & 2006 & 3853 & 2971 & 80903 & 898 & 10976 & $16.35 \%$ \\
daw_zgł_krew_4665_K+M & 2007 & 4107 & 3281 & 86237 & 1070 & 11739 & $17.43 \%$ \\
daw_zgł_krew_4665_K+M & 2008 & 4137 & 3263 & 86885 & 1146 & 11658 & $17.56 \%$ \\
daw_zgł_krew_4665_K+M & 2009 & 3999 & 3030 & 83978 & 1091 & 9964 & $16.97 \%$ \\
daw_zgł_krew_4665_K+M & 2010 & 3822 & 3058 & 80257 & 1199 & 9795 & $16.22 \%$ \\
Total & & & & 494725 & & $100 \%$ \\
\hline
\end{tabular}

daw_zgł_krew_4665_K+M - total number of donors (male +female) in the $46-65$ age category

Table 21. Number of donors aged 46-65 who reported to donate blood/blood components in the years 20052010 broken down into RBTCs

\begin{tabular}{|c|c|c|c|c|c|c|c|}
\hline Variable & RBTC & Average & Median & Total & Min & Max & $\%$ total \\
\hline daw_zgł_krew_4665_K+M & Bialystok & 2896 & 3081 & 17376 & 1999 & 3536 & $3.51 \%$ \\
\hline daw_zgł_krew_4665_K+M & Bydgoszcz & 5433 & 5456 & 32600 & 4834 & 5812 & $6.59 \%$ \\
\hline daw_zgł_krew_4665_K+M & Gdansk & 3822 & 3855 & 22931 & 3543 & 3936 & $4.64 \%$ \\
\hline daw_zgł_krew_4665_K+M & Kalisz & 3131 & 3198 & 18788 & 2710 & 3430 & $3.80 \%$ \\
\hline daw_zgł_krew_4665_K+M & Katowice & 8062 & 8072 & 48370 & 7699 & 8386 & $9.78 \%$ \\
\hline daw_zgł_krew_4665_K+M & Kielce & 2832 & 2890 & 16990 & 2305 & 3309 & $3.43 \%$ \\
\hline daw_zgł_krew_4665_K+M & Krakow & 5491 & 5577 & 32943 & 4972 & 5806 & $6.66 \%$ \\
\hline daw_zgł_krew_4665_K+M & Lublin & 3464 & 3378 & 20781 & 3030 & 3980 & $4.20 \%$ \\
\hline daw_zgł_krew_4665_K+M & Lodz & 5694 & 5582 & 34164 & 5306 & 6222 & $6.91 \%$ \\
\hline daw_zgł_krew_4665_K+M & Olsztyn & 2327 & 2359 & 13960 & 1987 & 2662 & $2.82 \%$ \\
\hline daw_zgł_krew_4665_K+M & Opole & 1893 & 1904 & 11357 & 1557 & 2206 & $2.30 \%$ \\
\hline daw_zgł_krew_4665_K+M & Poznan & 6719 & 6832 & 40316 & 5837 & 7250 & $8.15 \%$ \\
\hline daw_zgł_krew_4665_K+M & Raciborz & 2330 & 2293 & 13979 & 1802 & 3058 & $2.83 \%$ \\
\hline daw_zgł_krew_4665_K+M & Radom & 1596 & 1593 & 9576 & 1403 & 1775 & $1.94 \%$ \\
\hline daw_zgł_krew_4665_K+M & Rzeszow & 2423 & 2373 & 14539 & 2084 & 2938 & $2.94 \%$ \\
\hline daw_zgł_krew_4665_K+M & Slupsk & 1035 & 1081 & 6212 & 808 & 1199 & $1.26 \%$ \\
\hline daw_zgł_krew_4665_K+M & Szczecin & 2606 & 2566 & 15633 & 2449 & 2828 & $3.16 \%$ \\
\hline daw_zgł_krew_4665_K+M & Walbrzych & 2646 & 2698 & 15878 & 2202 & 2865 & $3.21 \%$ \\
\hline daw_zgł_krew_4665_K+M & Warsaw & 10870 & 11033 & 65222 & 9795 & 11739 & $13.18 \%$ \\
\hline daw_zgł_krew_4665_K+M & Wroclaw & 5541 & 5542 & 33243 & 4850 & 6223 & $6.72 \%$ \\
\hline daw_zgł_krew_4665_K+M & Zielona Gora & 1645 & 1645 & 9867 & 1326 & 1869 & $1.99 \%$ \\
\hline Total & & & & 494725 & & & $100 \%$ \\
\hline
\end{tabular}

daw_zgł_krew_4665_K+M - total number of donors (male +female) in the $46-65$ age category

the women population (Figure 9), the trend line for each variable indicates a clear upward trend for $18-30$ and $31-45$, and no distinctive trend for $46-65$. It can therefore be assumed that if the structure of the collected data had remained unchanged, a further increase in the population of men in the first two age groups would have been observed and the population of the 46-65 group would have been relatively constant (app. 65-68 thousand donors per year). 


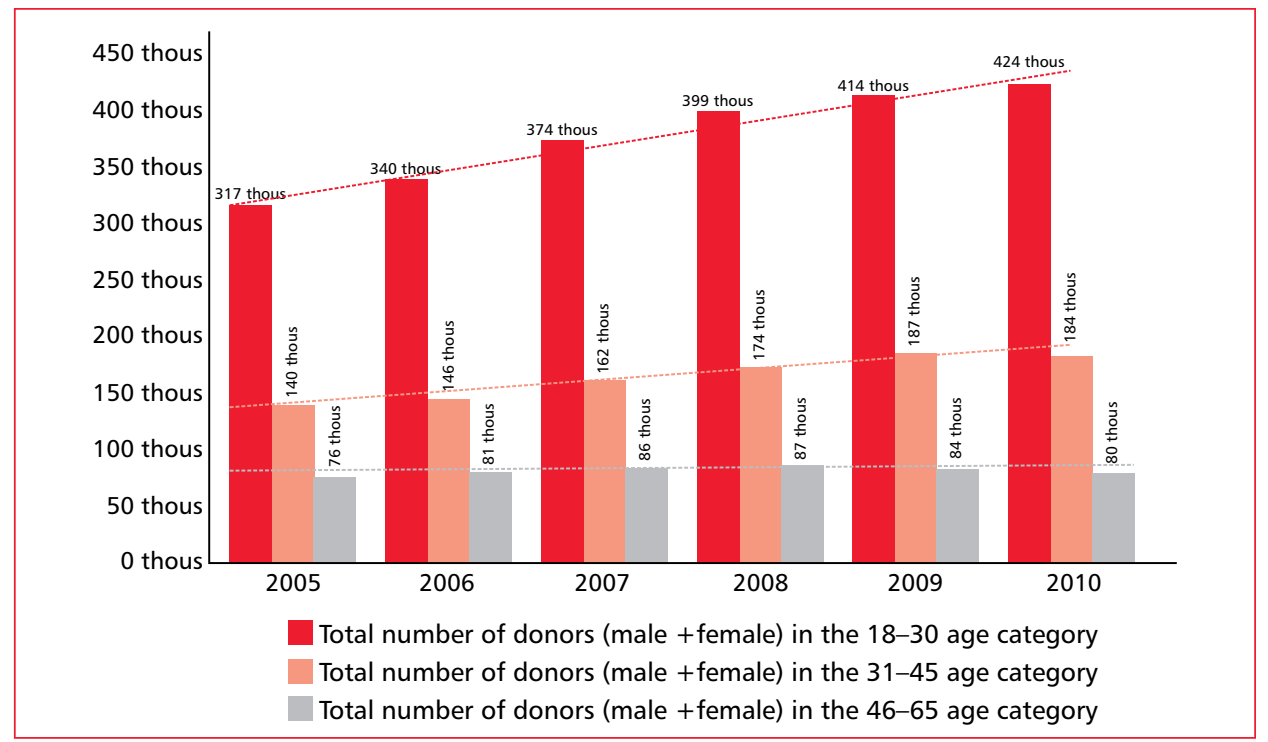

Figure 8. Number of donors who reported at RBTCs to donate blood/blood components in 2005-2010 broken down into age categories

Table 22. Characteristics of the population of female donors aged 18-30

\begin{tabular}{lccccccc}
\hline Variable & Year & Average & Median & Total & Min & Max & $\%$ total \\
\hline daw_zgł_krew_1830_K & 2005 & 4022 & 2963 & 84462 & 787 & 9489 & $12.43 \%$ \\
daw_zgł_krew_1830_K & 2006 & 4454 & 3305 & 93530 & 1066 & 10782 & $13.76 \%$ \\
daw_zgł_krew_1830_K & 2007 & 5138 & 3931 & 107894 & 1648 & 12928 & $15.88 \%$ \\
daw_zgł_krew_1830_K & 2008 & 5659 & 4274 & 118843 & 1893 & 13405 & $17.49 \%$ \\
daw_zgł_krew_1830_K & 2009 & 6243 & 4605 & 131112 & 2082 & 13286 & $19.29 \%$ \\
daw_zgł_krew_1830_K & 2010 & 6846 & 5012 & 143771 & 2656 & 14611 & $21.15 \%$ \\
Total & & & & $\mathbf{6 7 9 6 1 2}$ & & & $100 \%$ \\
\hline
\end{tabular}

daw_zgl_krew_1830_K - total number of female donors in the 18-30 age category

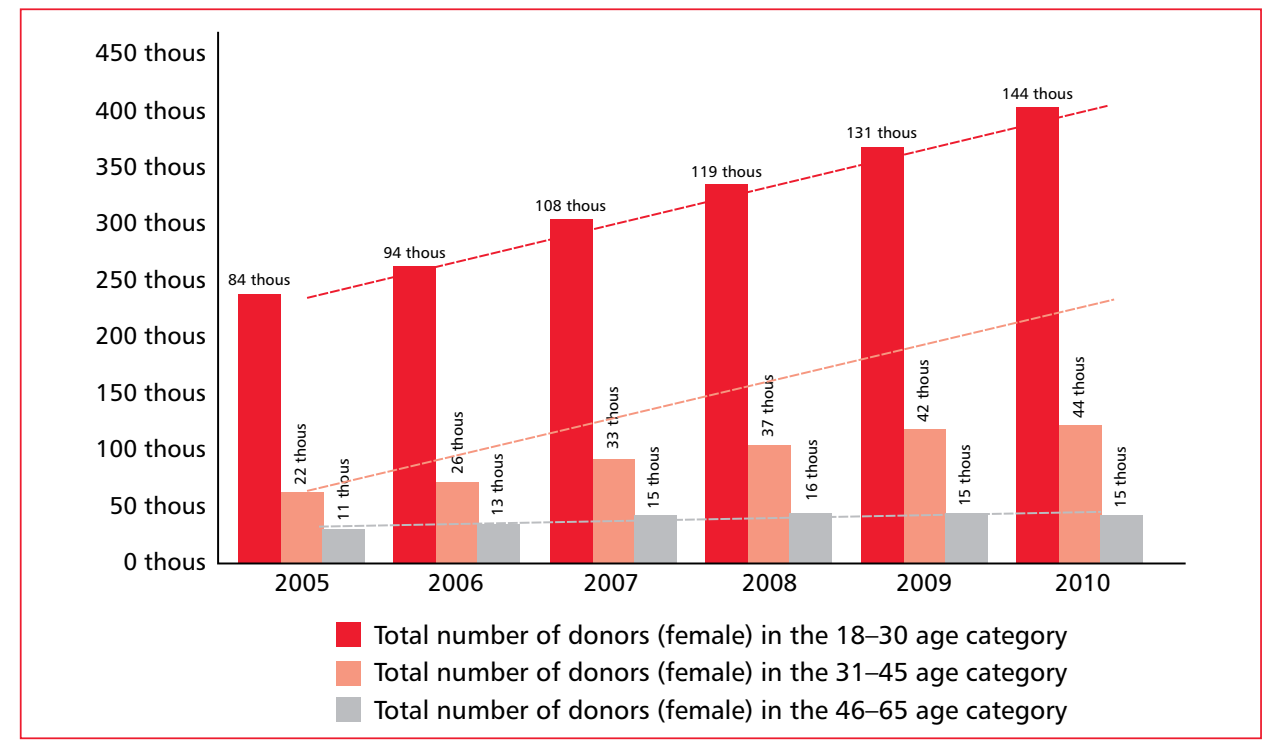

Figure 9. Number of women who reported to RBTCs for donation of blood/blood components in 2005-2010 broken down into age categories 
Table 23. Number of women aged 18-30 who reported to donate blood/blood components in 2005-2010 broken down into RBTCs

\begin{tabular}{|c|c|c|c|c|c|c|c|}
\hline Variable & RBTC & Average & Median & Total & Min & $\operatorname{Max}$ & $\%$ total \\
\hline daw_zgł_krew_1830_K & Bialystok & 4956 & 4588 & 29737 & 3523 & 7334 & $4.38 \%$ \\
\hline daw_zgł_krew_1830_K & Bydgoszcz & 7098 & 6948 & 42585 & 4909 & 9130 & $6.27 \%$ \\
\hline daw_zgł_krew_1830_K & Gdansk & 5523 & 5165 & 33137 & 3759 & 7745 & $4.88 \%$ \\
\hline daw_zgł_krew_1830_K & Kalisz & 3629 & 3886 & 21771 & 2676 & 4168 & $3.20 \%$ \\
\hline daw_zgł_krew_1830_K & Katowice & 8802 & 8591 & 52814 & 7219 & 10735 & $7.77 \%$ \\
\hline daw_zgł_krew_1830_K & Kielce & 3087 & 3116 & 18520 & 2705 & 3497 & $2.73 \%$ \\
\hline daw_zgł_krew_1830_K & Krakow & 8295 & 8224 & 49771 & 6471 & 10491 & $7.32 \%$ \\
\hline daw_zgł_krew_1830_K & Lublin & 7302 & 7385 & 43809 & 5850 & 8434 & $6.45 \%$ \\
\hline daw_zgł_krew_1830_K & Lodz & 7567 & 7137 & 45401 & 5839 & 10119 & $6.68 \%$ \\
\hline daw_zgł_krew_1830_K & Olsztyn & 3992 & 4469 & 23952 & 2326 & 5014 & $3.52 \%$ \\
\hline daw_zgł_krew_1830_K & Opole & 3694 & 3780 & 22161 & 2667 & 4605 & $3.26 \%$ \\
\hline daw_zgł_krew_1830_K & Poznan & 9334 & 9506 & 56003 & 5847 & 12093 & $8.24 \%$ \\
\hline daw_zgł_krew_1830_K & Raciborz & 2857 & 2822 & 17143 & 2255 & 3671 & $2.52 \%$ \\
\hline daw_zgł_krew_1830_K & Radom & 2411 & 2318 & 14468 & 1925 & 2897 & $2.13 \%$ \\
\hline daw_zgł_krew_1830_K & Rzeszow & 3707 & 3783 & 22239 & 2963 & 4296 & $3.27 \%$ \\
\hline daw_zgł_krew_1830_K & Slupsk & 1689 & 1771 & 10132 & 787 & 2656 & $1.49 \%$ \\
\hline daw_zgł_krew_1830_K & Szczecin & 3344 & 3114 & 20066 & 2264 & 5012 & $2.95 \%$ \\
\hline daw_zgł_krew_1830_K & Walbrzych & 2649 & 2648 & 15891 & 1901 & 3338 & $2.34 \%$ \\
\hline daw_zgł_krew_1830_K & Warsaw & 12417 & 13107 & 74501 & 9489 & 14611 & $10.96 \%$ \\
\hline daw_zgł_krew_1830_K & Wroclaw & 8595 & 8973 & 51570 & 5658 & 10687 & $7.59 \%$ \\
\hline daw_zgł_krew_1830_K & Zielona Gora & 2324 & 2248 & 13941 & 1066 & 3443 & $2.05 \%$ \\
\hline Total & & & & 679612 & & & $100 \%$ \\
\hline
\end{tabular}

daw_zgł_krew_1830_K - total number of female donors in the 18-30 age category

Table 24. Characteristics of the population of women aged 31-45 who reported in RBTCs to donate blood/blood components in 2005-2010 broken down into years

\begin{tabular}{lccccccc}
\hline Variable & Year & Average & Median & Total & Min & Max & $\%$ total \\
\hline daw_zgł_krew_3145_K & 2005 & 1064 & 744 & 22354 & 132 & 3382 & $10.99 \%$ \\
daw_zgł_krew_3145_k & 2006 & 1221 & 871 & 25640 & 217 & 3934 & $12.61 \%$ \\
daw_zgł_krew_3145_K & 2007 & 1557 & 1141 & 32692 & 376 & 5184 & $16.07 \%$ \\
daw_zgł_krew_3145_K & 2008 & 1782 & 1189 & 37417 & 389 & 5342 & $18.40 \%$ \\
daw_zgł_krew_3145_K & 2009 & 1989 & 1404 & 41765 & 442 & 5925 & $20.53 \%$ \\
daw_zgł_krew_3145_K & 2010 & 2073 & 1389 & 43524 & 605 & 5714 & $21.40 \%$ \\
Total & & & & 203392 & & & $100 \%$ \\
\hline
\end{tabular}

daw_zgl_krew_3145_K - total number of female donors in the $31-45$ age category

Group 2

The data demonstrates that a total of 4933916 donors reported at RBTCs in the period 2011-2017 with the intention of donating blood/blood components and 4931676 of them were in the 18-65 age category (i.e. eligible for blood donation).
A separate group were donors under 18 and above 65 who are eligible for donation only in exceptional situations. These donor groups were by far the least numerous - a total of 490 donors under 18 and 1750 donors over 65 . Therefore, as in the case of the data for the period 2005-2010, further 
Table 25. Number of women aged 31-45 who reported to donate blood/blood components in 2005-2010 broken down into RBTCs

\begin{tabular}{|c|c|c|c|c|c|c|c|}
\hline Variable & RBTC & Average & Median & Total & Min & Max & $\%$ total \\
\hline daw_zgł_krew_3145_K & Bialystok & 1358 & 1509 & 8150 & 744 & 1780 & $4.01 \%$ \\
\hline daw_zgł_krew_3145_K & Bydgoszcz & 2200 & 2269 & 13199 & 1269 & 2877 & $6.49 \%$ \\
\hline daw_zgł_krew_3145_K & Gdansk & 1878 & 1807 & 11270 & 1129 & 2658 & $5.54 \%$ \\
\hline daw_zgł_krew_3145_K & Kalisz & 1122 & 1165 & 6732 & 729 & 1404 & $3.31 \%$ \\
\hline daw_zgł_krew_3145_K & Katowice & 3119 & 3017 & 18712 & 2401 & 3879 & $9.20 \%$ \\
\hline daw_zgł_krew_3145_K & Kielce & 837 & 861 & 5024 & 667 & 969 & $2.47 \%$ \\
\hline daw_zgł_krew_3145_K & Krakow & 2222 & 2310 & 13331 & 1599 & 2680 & $6.55 \%$ \\
\hline daw_zgł_krew_3145_K & Lublin & 1493 & 1595 & 8956 & 916 & 1856 & $4.40 \%$ \\
\hline daw_zgł_krew_3145_K & Lodz & 2279 & 2402 & 13672 & 1516 & 2952 & $6.72 \%$ \\
\hline daw_zgł_krew_3145_K & Olsztyn & 905 & 916 & 5431 & 527 & 1234 & $2.67 \%$ \\
\hline daw_zgł_krew_3145_K & Opole & 974 & 1000 & 5846 & 511 & 1317 & $2.87 \%$ \\
\hline daw_zgł_krew_3145_K & Poznan & 3132 & 3208 & 18791 & 1720 & 4264 & $9.24 \%$ \\
\hline daw_zgł_krew_3145_K & Raciborz & 806 & 702 & 4833 & 441 & 1386 & $2.38 \%$ \\
\hline daw_zgł_krew_3145_K & Radom & 496 & 512 & 2975 & 327 & 636 & $1.46 \%$ \\
\hline daw_zgł_krew_3145_K & Rzeszow & 682 & 727 & 4089 & 372 & 959 & $2.01 \%$ \\
\hline daw_zgł_krew_3145_K & Slupsk & 360 & 383 & 2161 & 132 & 605 & $1.06 \%$ \\
\hline daw_zgł_krew_3145_K & Szczecin & 911 & 945 & 5466 & 518 & 1302 & $2.69 \%$ \\
\hline daw_zgł_krew_3145_K & Walbrzych & 976 & 1025 & 5856 & 678 & 1258 & $2.88 \%$ \\
\hline daw_zgł_krew_3145_K & Warsaw & 4914 & 5263 & 29481 & 3382 & 5925 & $14.49 \%$ \\
\hline daw_zgł_krew_3145_K & Wroclaw & 2554 & 2609 & 15325 & 1529 & 3348 & $7.53 \%$ \\
\hline daw_zgł_krew_3145_K & Zielona Gora & 682 & 655 & 4092 & 287 & 1052 & $2.01 \%$ \\
\hline Total & & & & 203392 & & & $100 \%$ \\
\hline
\end{tabular}

daw_zgł_krew_3145_K - total number of female donors in the 31-45 age category

Table 26. Characteristics of the women population aged 46-65 who reported to donate blood/blood components in 2005-2010 broken down into years

\begin{tabular}{lccccccc}
\hline Variable & Year & Average & Median & Total & Min & Max & $\%$ total \\
\hline daw_zgł_krew_4665_K & 2005 & 504 & 323 & 10576 & 39 & 1911 & $12.44 \%$ \\
daw_zgł_krew_4665_K & 2006 & 603 & 389 & 12668 & 89 & 2034 & $14.90 \%$ \\
daw_zgł_krew_4665_K & 2007 & 725 & 519 & 15224 & 149 & 2457 & $17.90 \%$ \\
daw_zgł_krew_4665_K & 2008 & 765 & 610 & 16066 & 184 & 2336 & $18.89 \%$ \\
daw_zgł_krew_4665_K & 2009 & 737 & 551 & 15479 & 200 & 1845 & $18.20 \%$ \\
daw_zgł_krew_4665_K & 2010 & 715 & 566 & 15022 & 222 & 1868 & $17.67 \%$ \\
Total & & & & $\mathbf{8 5 0 3 5}$ & & & $100 \%$ \\
\hline
\end{tabular}

daw_zgł_krew_4665_K - total number of female donors in the $46-65$ age category

analyses included only data referring to the 18-65 age group.

Among the multiple donors who reported at RBTCs to donate blood/blood components, the largest group (2 352 099) fell within the 25-44 age category ( $48 \%$ of the total donor population; 16001 at average). The least numerous group were donors aged 45-65 (548 $885>11 \%)$. Donors aged 18-24 were less numerous 2030692 (> $41 \%$ of the total donor population) (Table 34).

Table 35, Table 36 and Table 37 present data which characterize the donor population in each age category. 
Table 27. Number of women aged 46-65 who reported for blood/blood component donation in 2005-2010 broken down into RBTCs

\begin{tabular}{|c|c|c|c|c|c|c|c|}
\hline Variable & RBTC & Average & Median & Total & Min & Max & $\%$ total \\
\hline daw_zgł_krew_4665_K & Bialystok & 519 & 579 & 3116 & 323 & 636 & $3.66 \%$ \\
\hline daw_zgł_krew_4665_K & Bydgoszcz & 939 & 1024 & 5635 & 627 & 1110 & $6.63 \%$ \\
\hline daw_zgł_krew_4665_K & Gdansk & 659 & 672 & 3951 & 467 & 782 & $4.65 \%$ \\
\hline daw_zgł_krew_4665_K & Kalisz & 465 & 511 & 2791 & 306 & 551 & $3.28 \%$ \\
\hline daw_zgł_krew_4665_K & Katowice & 1341 & 1350 & 8047 & 1090 & 1501 & $9.46 \%$ \\
\hline daw_zgł_krew_4665_K & Kielce & 359 & 358 & 2152 & 299 & 407 & $2.53 \%$ \\
\hline daw_zgł_krew_4665_K & Krakow & 937 & 936 & 5623 & 791 & 1051 & $6.61 \%$ \\
\hline daw_zgł_krew_4665_K & Lublin & 590 & 581 & 3540 & 431 & 711 & $4.16 \%$ \\
\hline daw_zgł_krew_4665_K & Lodz & 1138 & 1183 & 6829 & 919 & 1323 & $8.03 \%$ \\
\hline daw_zgł_krew_4665_K & Olsztyn & 344 & 384 & 2064 & 207 & 437 & $2.43 \%$ \\
\hline daw_zgł_krew_4665_K & Opole & 353 & 375 & 2119 & 251 & 409 & $2.49 \%$ \\
\hline daw_zgł_krew_4665_K & Poznan & 1201 & 1278 & 7204 & 842 & 1451 & $8.47 \%$ \\
\hline daw_zgł_krew_4665_K & Raciborz & 375 & 363 & 2249 & 167 & 610 & $2.64 \%$ \\
\hline daw_zgł_krew_4665_K & Radom & 224 & 220 & 1345 & 181 & 271 & $1.58 \%$ \\
\hline daw_zgł_krew_4665_k & Rzeszow & 241 & 242 & 1445 & 148 & 363 & $1.70 \%$ \\
\hline daw_zgł_krew_4665_K & Slupsk & 147 & 167 & 883 & 39 & 222 & $1.04 \%$ \\
\hline daw_zgł_krew_4665_K & Szczecin & 316 & 346 & 1895 & 171 & 385 & $2.23 \%$ \\
\hline daw_zgł_krew_4665_K & Walbrzych & 489 & 502 & 2936 & 263 & 752 & $3.45 \%$ \\
\hline daw_zgł_krew_4665_K & Warsaw & 2075 & 1973 & 12451 & 1845 & 2457 & $14.64 \%$ \\
\hline daw_zgł_krew_4665_K & Wroclaw & 1226 & 1289 & 7355 & 902 & 1465 & $8.65 \%$ \\
\hline daw_zgł_krew_4665_K & Zielona Gora & 234 & 248 & 1405 & 103 & 315 & $1.65 \%$ \\
\hline Total & & & & 85035 & & & $100 \%$ \\
\hline
\end{tabular}

daw_zgł_krew_4665_K - total number of female donors in the $46-65$ age category

Table 28. Characteristics of the population of men aged 18-30 who reported to donate blood/blood components in 2005-2010, broken down into years

\begin{tabular}{lccccccc}
\hline Variable & Year & Average & Median & Total & Min & Max & $\%$ total \\
\hline daw_zgł_krew_1830_M & 2005 & 11079 & 11214 & 232653 & 3295 & 24884 & $14.65 \%$ \\
daw_zgł_krew_1830_M & 2006 & 11759 & 11903 & 246929 & 5343 & 25645 & $15.54 \%$ \\
daw_zgł_krew_1830_M & 2007 & 12663 & 12782 & 265930 & 5514 & 27652 & $16.74 \%$ \\
daw_zgł_krew_1830_M & 2008 & 13350 & 12139 & 280359 & 6158 & 27637 & $17.65 \%$ \\
daw_zgł_krew_1830_M & 2009 & 13466 & 12536 & 282794 & 5508 & 26573 & $17.80 \%$ \\
daw_zgł_krew_1830_M & 2010 & 13329 & 12130 & 279916 & 5610 & 26679 & $17.62 \%$ \\
Total & & & & $\mathbf{1 5 8 5 5 1}$ & & & $100 \%$ \\
\hline
\end{tabular}

daw_zgł_krew_1830_M - total number of male donors in the 18-30 age category

The data presented in Table 35 shows that the highest number in this age category (339 945) was reported in 2011 (16\% of the total donor population in this age category). The lowest recorded number was 3626 (in 2017) and the highest was 34930 (in 2011).

The largest group of donors are donors aged 25-44 . According to the data presented in Table 36 , the highest number of donors in this age group (368 198, i.e. $>15 \%$ of the general donor population in this age category) reported for donation in 2017. The lowest number was 2733 (in 2011); the highest 41240 (in 2017).

The least numerous group were donors in the 45-65 age category (548 885). The highest num- 


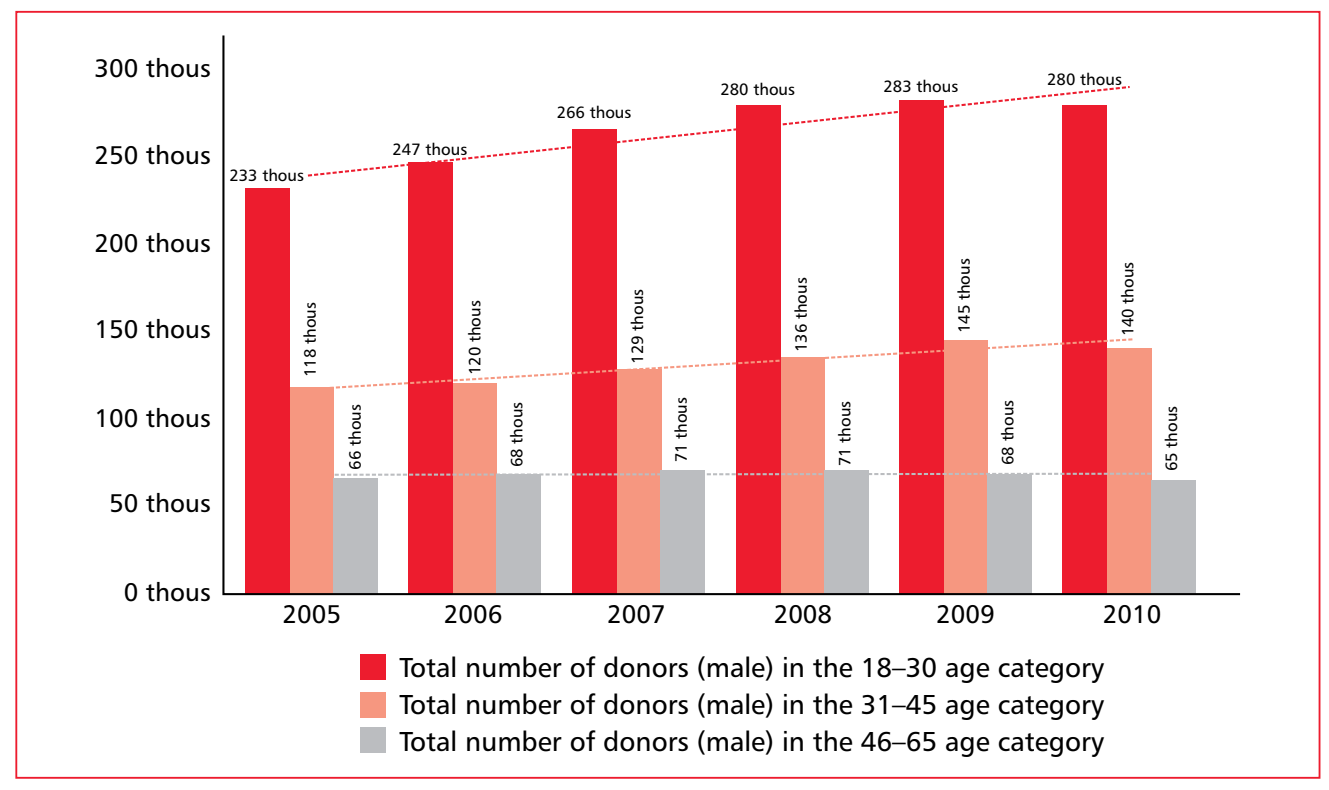

Figure 10. Number of men who reported at RBTCs to donate blood/blood components in 2005-2010 broken down into age categories

Table 29. Number of men aged 18-30 who reported in 2005-2010 to donate blood and blood components broken down into RBTCs

\begin{tabular}{|c|c|c|c|c|c|c|c|}
\hline Variable & RBTC & Average & Median & Total & Minimum & Maximum & $\%$ total \\
\hline daw_zgł_krew_1830_M & Bialystok & 12679 & 12933 & 76072 & 10733 & 13959 & $4.79 \%$ \\
\hline daw_zgł_krew_1830_M & Bydgoszcz & 15142 & 15463 & 90849 & 13540 & 15876 & $5.72 \%$ \\
\hline daw_zgł_krew_1830_M & Gdansk & 13078 & 13081 & 78469 & 11218 & 14561 & $4.94 \%$ \\
\hline daw_zgł_krew_1830_M & Kalisz & 7778 & 7988 & 46667 & 6904 & 8154 & $2.94 \%$ \\
\hline daw_zgł_krew_1830_M & Katowice & 19951 & 19548 & 119708 & 17201 & 23567 & $7.54 \%$ \\
\hline daw_zgł_krew_1830_M & Kielce & 7675 & 7558 & 46051 & 7077 & 8268 & $2.90 \%$ \\
\hline daw_zgł_krew_1830_M & Krakow & 18088 & 17699 & 108530 & 15498 & 20762 & $6.83 \%$ \\
\hline daw_zgł_krew_1830_M & Lublin & 17021 & 16842 & 102123 & 16557 & 18178 & $6.43 \%$ \\
\hline daw_zgł_krew_1830_M & Lodz & 15364 & 15062 & 92182 & 13516 & 17367 & $5.80 \%$ \\
\hline daw_zgł_krew_1830_M & Olsztyn & 12512 & 12039 & 75070 & 11126 & 14346 & $4.73 \%$ \\
\hline daw_zgł_krew_1830_M & Opole & 6756 & 7217 & 40538 & 3295 & 8852 & $2.55 \%$ \\
\hline daw_zgł_krew_1830_M & Poznan & 19685 & 20425 & 118110 & 16248 & 22231 & $7.43 \%$ \\
\hline daw_zgł_krew_1830_M & Raciborz & 6748 & 6615 & 40488 & 5037 & 8616 & $2.55 \%$ \\
\hline daw_zgł_krew_1830_M & Radom & 5574 & 5562 & 33442 & 4829 & 6158 & $2.11 \%$ \\
\hline daw_zgł_krew_1830_M & Rzeszow & 11094 & 10955 & 66562 & 10108 & 12536 & $4.19 \%$ \\
\hline daw_zgł_krew_1830_M & Slupsk & 6328 & 6014 & 37968 & 5232 & 7860 & $2.39 \%$ \\
\hline daw_zgł_krew_1830_M & Szczecin & 11940 & 11948 & 71641 & 11409 & 12303 & $4.51 \%$ \\
\hline daw_zgł_krew_1830_M & Walbrzych & 6085 & 5966 & 36508 & 5699 & 7049 & $2.30 \%$ \\
\hline daw_zgł_krew_1830_M & Warsaw & 26512 & 26626 & 159070 & 24884 & 27652 & $10.01 \%$ \\
\hline daw_zgł_krew_1830_M & Wroclaw & 15800 & 16192 & 94798 & 12471 & 18191 & $5.97 \%$ \\
\hline daw_zgł_krew_1830_M & Zielona Gora & 8956 & 8593 & 53735 & 7800 & 11655 & $3.38 \%$ \\
\hline Total & & & & 1588581 & & & $100 \%$ \\
\hline
\end{tabular}

daw_zgł_krew_1830_M - total number of male donors in the 18-30 age category 
Table 30. Characteristics of the male population aged 31-45 who reported for blood/blood component donation in 2005-2010 broken down into years

\begin{tabular}{lccccccc}
\hline Variable & Year & Average & Median & Total & Min & Max & $\%$ total \\
\hline daw_zgł_krew_3145_M & 2005 & 5614 & 4423 & 117888 & 1404 & 15063 & $14.95 \%$ \\
daw_zgł_krew_3145_M & 2006 & 5721 & 4418 & 120136 & 1415 & 15498 & $15.24 \%$ \\
daw_zgł_krew_3145_M & 2007 & 6144 & 4909 & 129020 & 1684 & 16913 & $16.36 \%$ \\
daw_zgł_krew_3145_M & 2008 & 6481 & 4753 & 136092 & 1873 & 17795 & $17.26 \%$ \\
daw_zgł_krew_3145_M & 2009 & 6899 & 5116 & 144872 & 1790 & 18031 & $18.37 \%$ \\
daw_zgł_krew_3145_M & 2010 & 6686 & 5032 & 140413 & 2168 & 17335 & $17.81 \%$ \\
Total & & & & $\mathbf{7 8 8 4 2 1}$ & & & $100 \%$ \\
\hline
\end{tabular}

daw_zgł_krew_3145_M - total number of male donors in the 31-45 age category

Table 31. Number of men aged 31-45 who reported for blood/blood component donation in 2005-2010 broken down into RBTCs

\begin{tabular}{|c|c|c|c|c|c|c|c|}
\hline Variable & RBTC & Average & Median & Total & Min & Max & $\%$ total \\
\hline daw_zgł_krew_3145_M & Białystok & 5616 & 5563 & 33696 & 3342 & 8902 & $4.27 \%$ \\
\hline daw_zgł_krew_3145_M & Bydgoszcz & 7598 & 7669 & 45587 & 6778 & 8511 & $5.78 \%$ \\
\hline daw_zgł_krew_3145_M & Gdansk & 6861 & 6617 & 41166 & 6216 & 7710 & $5.22 \%$ \\
\hline daw_zgł_krew_3145_M & Kalisz & 4379 & 4425 & 26275 & 3980 & 4705 & $3.33 \%$ \\
\hline daw_zgł_krew_3145_M & Katowice & 12952 & 12737 & 77710 & 12064 & 14246 & $9.86 \%$ \\
\hline daw_zgł_krew_3145_M & Kielce & 3873 & 3827 & 23239 & 3703 & 4200 & $2.95 \%$ \\
\hline daw_zgł_krew_3145_M & Krakow & 8992 & 8934 & 53951 & 8424 & 9554 & $6.84 \%$ \\
\hline daw_zgł_krew_3145_M & Lublin & 6197 & 6201 & 37181 & 5629 & 6761 & $4.72 \%$ \\
\hline daw_zgł_krew_3145_M & Lodz & 7723 & 7926 & 46339 & 6788 & 8376 & $5.88 \%$ \\
\hline daw_zgł_krew_3145_M & Olsztyn & 4147 & 4123 & 24879 & 3724 & 4826 & $3.16 \%$ \\
\hline daw_zgł_krew_3145_M & Opole & 2917 & 2848 & 17499 & 2551 & 3533 & $2.22 \%$ \\
\hline daw_zgł_krew_3145_M & Poznan & 11336 & 11404 & 68014 & 9163 & 13365 & $8.63 \%$ \\
\hline daw_zgł_krew_3145_M & Raciborz & 4784 & 4583 & 28702 & 4371 & 5650 & $3.64 \%$ \\
\hline daw_zgł_krew_3145_M & Radom & 2330 & 2323 & 13980 & 2204 & 2477 & $1.77 \%$ \\
\hline daw_zgł_krew_3145_M & Rzeszow & 4308 & 4237 & 25849 & 3738 & 5116 & $3.28 \%$ \\
\hline daw_zgł_krew_3145_M & Slupsk & 1722 & 1737 & 10334 & 1404 & 2168 & $1.31 \%$ \\
\hline daw_zgł_krew_3145_M & Szczecin & 4881 & 4891 & 29285 & 4753 & 5032 & $3.71 \%$ \\
\hline daw_zgł_krew_3145_M & Walbrzych & 3445 & 3399 & 20672 & 3282 & 3782 & $2.62 \%$ \\
\hline daw_zgł_krew_3145_M & Warsaw & 16773 & 17124 & 100635 & 15063 & 18031 & $12.76 \%$ \\
\hline daw_zgł_krew_3145_M & Wroclaw & 8014 & 7943 & 48084 & 6417 & 9531 & $6.10 \%$ \\
\hline daw_zgł_krew_3145_M & Zielona Gora & 2557 & 2516 & 15344 & 2058 & 3105 & $1.95 \%$ \\
\hline Total & & & & 788421 & & & $100 \%$ \\
\hline
\end{tabular}

daw_zgt_krew_3145_M - total number of male donors in the 31-45 age category

ber of these donors reported for donation in 2017 (82 024 , i.e. almost $15 \%$ of the overall donation population in this age category); the lowest in 2014 (76 045, i.e. $<14 \%$ ). The minimum and maximum numbers were recorded in 2011 (Table 37 ).

Summary of data referring to specific age categories of men who reported in RBTCs in the period 2011-2017 with the intention of donating blood/blood components is presented in Figure 11. The trend lines for each variable indicate a clear upward trend for the most numerous 25-44 age category and a distinctive lower trend for 18-24. There is no distinctive trend for 46-65 age category which may lead to an assumption that this age group will remain relatively stable (app. 80 thousand donors per year). 
Table 32. Characteristics of the male donor population aged 46-65 who reported at RBTCs to donate blood/blood components in 2005-2010 broken down into years

\begin{tabular}{lccccccc}
\hline Variable & Year & Average & Median & Total & Min & Max & $\%$ total \\
\hline daw_zgł_krew_4665_M & 2005 & 3138 & 2404 & 65889 & 769 & 9179 & $16.08 \%$ \\
daw_zgł_krew_4665_M & 2006 & 3249 & 2578 & 68235 & 809 & 8942 & $16.66 \%$ \\
daw_zgł_krew_4665_M & 2007 & 3382 & 2762 & 71013 & 921 & 9282 & $17.33 \%$ \\
daw_zgł_krew_4665_M & 2008 & 3372 & 2718 & 70819 & 962 & 9322 & $17.29 \%$ \\
daw_zgł_krew_4665_M & 2009 & 3262 & 2454 & 68499 & 891 & 8119 & $16.72 \%$ \\
daw_zgł_krew_4665_M & 2010 & 3106 & 2448 & 65235 & 977 & 7927 & $15.92 \%$ \\
Total & & & 409690 & & & $100 \%$ \\
\hline
\end{tabular}

daw_zgł_krew_4665_M - total number of male donors in the $46-65$ age category

Table 33. Number of men aged 46-65 who reported in to donate blood/blood components in 2005-2010 broken down into RBTCs

\begin{tabular}{|c|c|c|c|c|c|c|c|}
\hline Variable & RBTC & Average & Median & Total & Min & Max & $\%$ total \\
\hline daw_zgł_krew_4665_M & Bialystok & 2377 & 2502 & 14260 & 1676 & 2900 & $3.48 \%$ \\
\hline daw_zgł_krew_4665_M & Bydgoszcz & 4494 & 4535 & 26965 & 4207 & 4732 & $6.58 \%$ \\
\hline daw_zgł_krew_4665_M & Gdansk & 3163 & 3162 & 18980 & 3076 & 3254 & $4.63 \%$ \\
\hline daw_zgł_krew_4665_M & Kalisz & 2666 & 2687 & 15997 & 2404 & 2879 & $3.90 \%$ \\
\hline daw_zgł_krew_4665_M & Katowice & 6721 & 6665 & 40323 & 6314 & 7136 & $9.84 \%$ \\
\hline daw_zgł_krew_4665_M & Kielce & 2473 & 2494 & 14838 & 2006 & 2944 & $3.62 \%$ \\
\hline daw_zgł_krew_4665_M & Krakow & 4553 & 4673 & 27320 & 4106 & 4818 & $6.67 \%$ \\
\hline daw_zgł_krew_4665_M & Lublin & 2874 & 2835 & 17241 & 2454 & 3269 & $4.21 \%$ \\
\hline daw_zgł_krew_4665_M & Lodz & 4556 & 4471 & 27335 & 4192 & 4915 & $6.67 \%$ \\
\hline daw_zgł_krew_4665_M & Olsztyn & 1983 & 1975 & 11896 & 1780 & 2225 & $2.90 \%$ \\
\hline daw_zgł_krew_4665_M & Opole & 1540 & 1530 & 9238 & 1252 & 1801 & $2.25 \%$ \\
\hline daw_zgł_krew_4665_M & Poznan & 5519 & 5568 & 33112 & 4995 & 5859 & $8.08 \%$ \\
\hline daw_zgł_krew_4665_M & Raciborz & 1955 & 1924 & 11730 & 1635 & 2448 & $2.86 \%$ \\
\hline daw_zgł_krew_4665_M & Radom & 1372 & 1406 & 8231 & 1177 & 1504 & $2.01 \%$ \\
\hline daw_zgł_krew_4665_M & Rzeszow & 2182 & 2120 & 13094 & 1936 & 2575 & $3.20 \%$ \\
\hline daw_zgł_krew_4665_M & Slupsk & 888 & 906 & 5329 & 769 & 977 & $1.30 \%$ \\
\hline daw_zgł_krew_4665_M & Szczecin & 2290 & 2288 & 13738 & 2073 & 2475 & $3.35 \%$ \\
\hline daw_zgł_krew_4665_M & Walbrzych & 2157 & 2303 & 12942 & 1450 & 2382 & $3.16 \%$ \\
\hline daw_zgł_krew_4665_M & Warsaw & 8795 & 9061 & 52771 & 7927 & 9322 & $12.88 \%$ \\
\hline daw_zgł_krew_4665_M & Wroclaw & 4315 & 4270 & 25888 & 3948 & 4758 & $6.32 \%$ \\
\hline daw_zgł_krew_4665_M & Zielona Gora & 1410 & 1426 & 8462 & 1223 & 1572 & $2.07 \%$ \\
\hline Total & & & & 409690 & & & $100 \%$ \\
\hline
\end{tabular}

daw_zgł_krew_4665_M - total number of male donors in the $46-65$ age category

Female donors

The most numerous group were women aged 18-24, and the least numerous, aged 45-65 (Figure 12).

In 2011 , the highest number of women aged 18-24 was recorded - a total of 127783 ( $>15 \%$ of the female donor population in this age category). The lowest value was recorded in
2017 at RBTC in Walbrzych (1433); the highest in 2011 (12 845) at RBTC in Poznan (Table 38, Table 39).

Women aged 25-44 were the middle group (629 236). Most women in this age category reported for donation in 2016 (99 617, 15.83\%). The minimum number recorded was 640 women in 2011 who reported for donation in RBTC in Slupsk; the 
Table 34. Total number of donors who reported at RBTCs for donation of blood/blood components in the period 2011-2017 broken down into age categories

\begin{tabular}{lcccccc}
\hline Variable & Average & Median & Total & Minimum & Maximum & $\%$ total \\
\hline daw_zgł_krew_1824_K+M & 13814 & 13254 & 2030692 & 3626 & 34930 & $41.16 \%$ \\
daw_zgł_krew_2544_K+M & 16001 & 13633 & 2352099 & 2733 & 41240 & $47.67 \%$ \\
daw_zgł_krew_4565_K+M & 3734 & 3185 & 548885 & 1082 & 9365 & $11.12 \%$ \\
daw_zgł_krew_m18_K+M & 3 & 0 & 490 & 0 & 57 & $0.01 \%$ \\
daw_zgł_krew_w65_K+M & 12 & 7 & 1750 & 0 & 55 & $0.04 \%$ \\
Total & & & 4933916 & & $100 \%$ \\
\hline
\end{tabular}

daw_zgl_krew_1824_K+M - total number of donors (male +female) in the 18-24 age category daw_zgl_krew_2544 K+M - total number of donors (male + female) in the 25-44 age category daw_zgl_krew_4565_K+M - total number of donors (male +female) in the 45-65 age category

daw_zgl_krew_m18-K+M - total number of donors (male + female) below 18

daw_zgl_krew_w65_K+M - total number of donors (male + female) above 65

Table 35. Characteristics of the donor population aged 18-24 who reported for blood donation in 2011-2017 broken down into years

\begin{tabular}{lccccccc}
\hline Variable & Year & Average & Median & Total & Min & Max & $\%$ total \\
\hline daw_zgł_krew_1824_K+M & 2011 & 16188 & 16070 & 339945 & 6045 & 34930 & $16.74 \%$ \\
daw_zgł_krew_1824_K+M & 2012 & 14802 & 13000 & 310847 & 5418 & 28252 & $15.31 \%$ \\
daw_zgł_krew_1824_K+M & 2014 & 13615 & 13427 & 285910 & 4789 & 27660 & $14.08 \%$ \\
daw_zgł_krew_1824_K+M & 2013 & 14378 & 12512 & 301929 & 4945 & 27285 & $14.87 \%$ \\
daw_zgł_krew_1824_K+M & 2015 & 13555 & 13304 & 284650 & 4512 & 26614 & $14.02 \%$ \\
daw_zgł_krew_1824_K+M & 2016 & 12658 & 13639 & 265818 & 4140 & 23882 & $13.09 \%$ \\
daw_zgł_krew_1824_K+M & 2017 & 11504 & 11773 & 241593 & 3626 & 22315 & $11.90 \%$ \\
Total & & & & $\mathbf{2 0 3 0 6 9 2}$ & & & $100 \%$ \\
\hline
\end{tabular}

daw_zgł_krew_1824_K+M - total number of male and female donors in the 18-24 age category

maximum number (12 620) was recorded in 2015 in Warsaw (Table 40, Table 41).

In the 45-65 age category a total of 121530 female donors was reported. The highest number reported for donation in 2017 (20 149, i.e > 16\% of the overall female general population in this age category). The highest value was recorded in 2017 (2204) and the lowest in 2011 (209) in the RBTCs in Warsaw and Slupsk respectively (Table 42, Table 43).

Summary of data referring to specific age categories of women who reported in RBTCs in the period $2011-2017$ with the intention of donating blood/blood components is presented in Figure 12. As in the case of the general donor population (Figure 11), the trend lines for each variable indicate a clear upward trend for the most numerous $25-44$ age category and a distinctive lower trend for 18-24 category. There is no distinctive trend for 45-65 age category, which may lead to an assumption that this age group will remain relatively stable (app. 20 thousand donors per year).

\section{Male donors}

Unlike in the case of women, the most numerous group of men donors were in the 25-44 age category; while the least numerous was the 45-65 age category as was the case with women donors (Figure 13).

In the period 2011-2017 a total of 1208805 donors in the 18-24 age group were recorded. The highest number of donors in this age-category was recorded in 2011 (212 162, i.e. $>17 \%$ of the total donor population in this age-category). The lowest value was recorded in 2017 (2193) at the RBTC in Walbrzych, and the highest in 2011 (22 085) at the RBTC in Poznan (Table 44, Table 45).

Men aged 25-44 were a group of donors - estimated at a total of 1722863 . The highest number (269 971) reported for donation in 2017 ( $>15 \%$ of the donor population in this age category). In the same year, the highest value (29 326) was recorded at RBTC in Warsaw. The lowest value (2093) was recorded in the RBTC in Slupsk (Table 46, Table 47). 
Table 36. Characteristics of the donor population aged 25-44 who reported for blood/blood component donation in 2011-2017 broken down into years

\begin{tabular}{lccccccc}
\hline Variable & Year & Average & Median & Total & Min & Max & $\%$ total \\
\hline daw_zgł_krew_2544_K+M & 2011 & 13463 & 11278 & 282729 & 2733 & 37120 & $12.02 \%$ \\
daw_zgł_krew_2544_K+M & 2012 & 15202 & 12248 & 319249 & 4937 & 37869 & $13.57 \%$ \\
daw_zgł_krew_2544_K+M & 2013 & 15534 & 12176 & 326209 & 5396 & 38825 & $13.87 \%$ \\
daw_zgł_krew_2544_K+M & 2014 & 16114 & 13527 & 338401 & 5630 & 39572 & $14.39 \%$ \\
daw_zgł_krew_2544_K+M & 2015 & 16945 & 15250 & 355844 & 5813 & 41113 & $15.13 \%$ \\
daw_zgł_krew_2544_K+M & 2016 & 17213 & 14728 & 361469 & 5400 & 40387 & $15.37 \%$ \\
daw_zgł_krew_2544_K+M & 2017 & 17533 & 15788 & 368198 & 6185 & 41240 & $15.65 \%$ \\
Total & & & & $\mathbf{2} 352099$ & & & $100 \%$ \\
\hline
\end{tabular}

daw_zgł_krew_2544_K+M - total number of male and female donors in the 25-44 age category

Table 37. Characteristics of the donor population aged 45-65 who reported for blood/blood component donation in 2011-2017 broken down into years

\begin{tabular}{lccccccc}
\hline Variable & Year & Average & Median & Total & Min & Max & $\%$ total \\
\hline daw_zgł_krew_4565_K+M & 2011 & 3754 & 3251 & 78825 & 1082 & 9365 & $14.36 \%$ \\
daw_zgł_krew_4565_K+M & 2012 & 3675 & 2700 & 77171 & 1139 & 9024 & $14.06 \%$ \\
daw_zgł_krew_4565_K+M & 2013 & 3706 & 2904 & 77826 & 1216 & 8886 & $14.18 \%$ \\
daw_zgł_krew_4565_K+M & 2014 & 3621 & 3012 & 76045 & 1217 & 8523 & $13.85 \%$ \\
daw_zgł_krew_4565_K+M & 2015 & 3721 & 3259 & 78133 & 1254 & 8442 & $14.23 \%$ \\
daw_zgł_krew_4565_K+M & 2016 & 3755 & 3318 & 78861 & 1329 & 8613 & $14.37 \%$ \\
daw_zgł_krew_4565_K+M & 2017 & 3906 & 3423 & 82024 & 1371 & 8829 & $14.94 \%$ \\
Total & & & & 548885 & & & $100 \%$ \\
\hline
\end{tabular}

daw_zgł_krew_4565_K+M - total number of male and female donors in the $45-65$ age category

In the years $2011-2017$ a total of 427355 donors aged 45-65 reported at RBTCs to donate blood/blood components. The highest number (63 431) reported in 2011 (15\% of the donor population in this age category). In the same year, the highest value (7473) was recorded in RBTC in Warsaw and the lowest (873) in RBTC in Slupsk (Table 48 and Table 49).

Summary of data referring to specific age categories of men who reported in RBTCs in the period 2011-2017 with the intention of donating blood/blood components is presented in Figure 13. As in the case of the general donor population (Figure 11) and the population of female donors (Figure 12), the trend lines for each variable indicate a clear upward trend for the most numerous 25-44 age category and a distinctive lower trend for 18-24 category. There is no distinctive trend for 45-65 age category, which may lead to an assumption that this age group will remain relatively stable (app. 60 thousand donors per year).
Figure 14 is a summing up of data on donor age-categories which were described in Group 1 and Group 2. As already mentioned, the data demonstrates that in group 1 the most numerous donor population was in the 18-30 age category, while in group 2 , the trend changed and the most numerous group were donors in the 25-44 age category.

Figure 15 presents combined data with regard to donor age within the 18-45 age category. Despite differences in individual age categories, this donor population has remained relatively stable in the last several years (at a level of app. 600 thousand).

\section{Discussion}

The study is a presentation of the donor population who reported at the RBTCs in the period 2005-2017 with the intention of donating blood/ /blood components. 


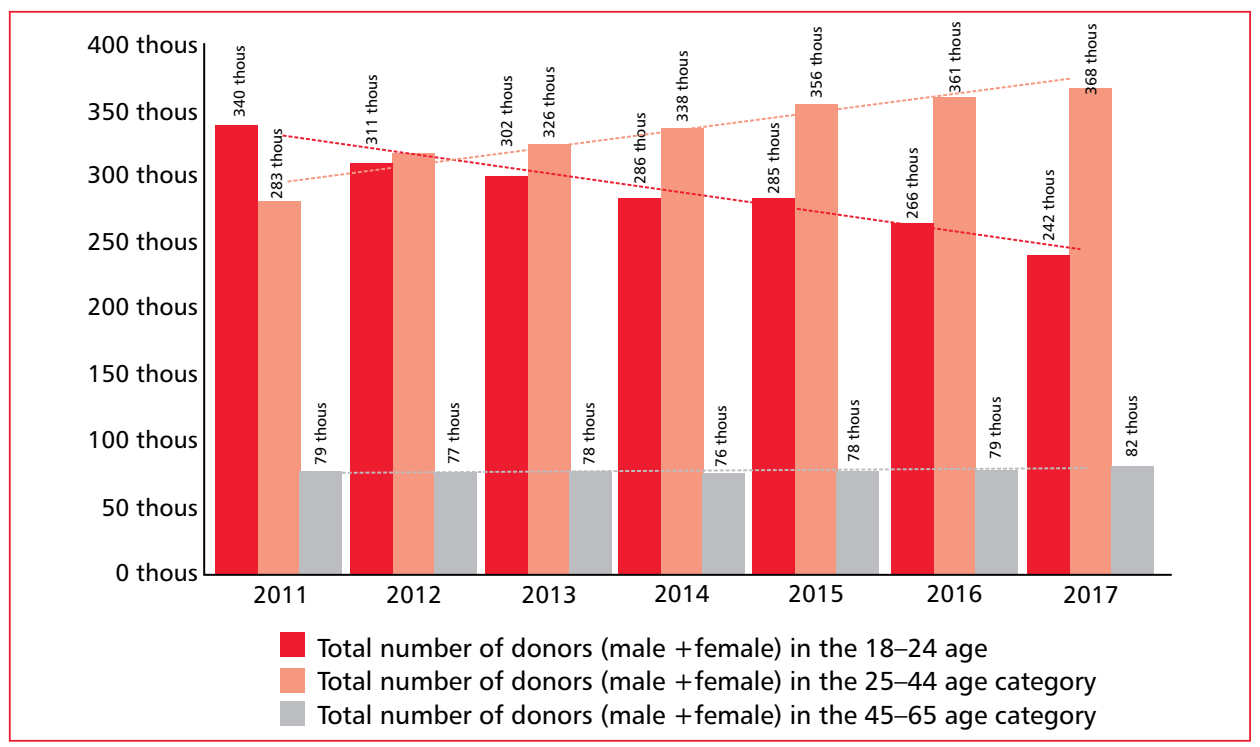

Figure 11. Number of donors (women and men) who reported at RBTCs to donate blood/blood components in 2011-2017 broken down into age categories

Table 38. Characteristics of the population of women aged 18-24 who reported for donation of blood/blood components in 2011-2017 broken down into years

\begin{tabular}{lccccccc}
\hline Variable & Year & Average & Median & Total & Min & Max & $\%$ total \\
\hline daw_zgł_krew_1824_K & 2011 & 6085 & 5577 & 127783 & 2582 & 12845 & $15.55 \%$ \\
daw_zgł_krew_1824_K & 2012 & 5692 & 4602 & 119533 & 2222 & 11665 & $14.54 \%$ \\
daw_zgł_krew_1824_K & 2013 & 5705 & 4455 & 119800 & 2146 & 11245 & $14.58 \%$ \\
daw_zgł_krew_1824_K & 2014 & 5637 & 4973 & 118378 & 1919 & 11817 & $14.40 \%$ \\
daw_zgł_krew_1824_K & 2015 & 5687 & 5366 & 119425 & 1896 & 11707 & $14.53 \%$ \\
daw_zgł_krew_1824_K & 2016 & 5414 & 5633 & 113698 & 1780 & 10451 & $13.83 \%$ \\
daw_zgł_krew_1824_K & 2017 & 4918 & 4949 & 103270 & 1433 & 9755 & $12.56 \%$ \\
Total & & & & $\mathbf{8 2 1 8 8 7}$ & & & $\mathbf{1 0 0 \%}$ \\
\hline
\end{tabular}

daw_zgt_krew_1824_K - total number of female donors in the 18-24 age category

Analysis of demographic data indicates that the demand for blood/blood components will increase in the nearest future. As result of the rapidly ageing population, the overall number of people who may require blood therapy will be growing steadily. On the other hand, the same process will bring about decline in the population of 18-65 aged donors eligible for blood donation. Decline in the population of potential blood donors is also affected by other factors such as falling birth rate and growing number of young people emigrating for permanent residence. Central Statistical Office (GUS) forecasts that by 2050 the population of Poland will decrease by over 4 million. The working age population, i.e. the source of potential blood donors, will decline by about 5 million $[2,3]$. This is likely to cause serious shortage of blood/blood components.

The number of blood donations in Poland has recently reached the limit of approximately 1200000 donations per year and to exceed this limit will be no easy task. All efforts must therefore be focused on promotion of voluntary blood donation and on motivating people to donate.

Reduction of population is a significant problem worldwide and the consequences of these changes will have to be faced sooner or later. In numerous publications the demographic situation in individual countries with regard to prognoses/forecasts for size of donor population, 


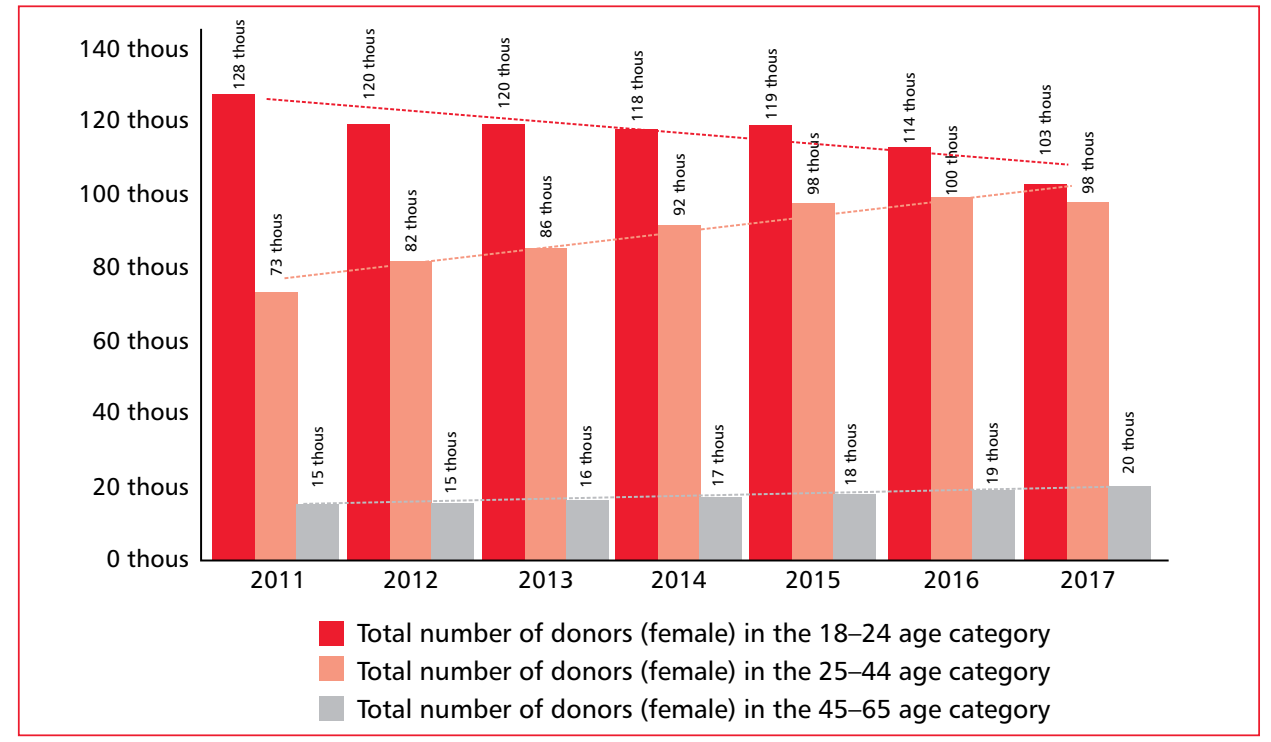

Figure 12. Number of women who reported at RBTCs to donate blood/blood components in 2011-2017 broken down into age groups

Table 39. Number of women aged 18-24 who reported for donation of blood/blood components in the years 2011-2017 broken down into RBTCs

\begin{tabular}{|c|c|c|c|c|c|c|c|}
\hline Variable & RBTC & Average & Median & Total & Min & Max & $\%$ total \\
\hline daw_zgł_krew_1824_K & Bialystok & 6231 & 6385 & 43620 & 4752 & 7214 & $5.31 \%$ \\
\hline daw_zgł_krew_1824_K & Bydgoszcz & 7573 & 7748 & 53009 & 6667 & 8207 & $6.45 \%$ \\
\hline daw_zgł_krew_1824_K & Gdansk & 6402 & 6077 & 44817 & 5805 & 8185 & $5.45 \%$ \\
\hline daw_zgł_krew_1824_K & Kalisz & 3556 & 3502 & 24890 & 3335 & 3968 & $3.03 \%$ \\
\hline daw_zgł_krew_1824_K & Katowice & 7380 & 7500 & 51663 & 5619 & 8178 & $6.29 \%$ \\
\hline daw_zgł_krew_1824_K & Kielce & 3608 & 3508 & 25258 & 3192 & 4244 & $3.07 \%$ \\
\hline daw_zgł_krew_1824_K & Krakow & 10651 & 10830 & 74559 & 9162 & 11665 & $9.07 \%$ \\
\hline daw_zgł_krew_1824_K & Lublin & 5835 & 5724 & 40846 & 4949 & 6505 & $4.97 \%$ \\
\hline daw_zgł_krew_1824_K & Lodz & 8271 & 8413 & 57900 & 7447 & 8575 & $7.04 \%$ \\
\hline daw_zgł_krew_1824_K & Olsztyn & 4429 & 4343 & 31000 & 3692 & 5577 & $3.77 \%$ \\
\hline daw_zgł_krew_1824_K & Opole & 2828 & 2623 & 19796 & 2278 & 3642 & $2.41 \%$ \\
\hline daw_zgł_krew_1824_K & Poznan & 10034 & 9641 & 70235 & 8975 & 12845 & $8.55 \%$ \\
\hline daw_zgł_krew_1824_K & Raciborz & 2252 & 1964 & 15762 & 1740 & 3647 & $1.92 \%$ \\
\hline daw_zgł_krew_1824_K & Radom & 2814 & 2894 & 19696 & 2510 & 3048 & $2.40 \%$ \\
\hline daw_zgł_krew_1824_K & Rzeszow & 5303 & 5404 & 37122 & 4455 & 6171 & $4.52 \%$ \\
\hline daw_zgł_krew_1824_K & Slupsk & 2210 & 2222 & 15470 & 1867 & 2712 & $1.88 \%$ \\
\hline daw_zgł_krew_1824_K & Szczecin & 4185 & 4171 & 29295 & 3707 & 4467 & $3.56 \%$ \\
\hline daw_zgł_krew_1824_K & Walbrzych & 2046 & 2110 & 14319 & 1433 & 2582 & $1.74 \%$ \\
\hline daw_zgł_krew_1824_K & Warsaw & 11063 & 11162 & 77442 & 9755 & 11817 & $9.42 \%$ \\
\hline daw_zgł_krew_1824_K & Wroclaw & 7642 & 7869 & 53497 & 6661 & 8169 & $6.51 \%$ \\
\hline daw_zgł_krew_1824_K & Zielona Gora & 3099 & 3001 & 21691 & 2500 & 4125 & $2.64 \%$ \\
\hline Total & & & & 821887 & & & $100 \%$ \\
\hline
\end{tabular}

daw_zgł_krew_1824_K — total number of female donors in the 18-24 age category 
Table 40. Characteristics of the female population aged 25-44 who reported for donation of blood/blood components in 2011-2017 broken down into years

\begin{tabular}{lccccccc}
\hline Variable & Year & Average & Median & Total & Min & Max & $\%$ total \\
\hline daw_zgł_krew_2544_K & 2011 & 3499 & 2417 & 73476 & 640 & 10054 & $11.68 \%$ \\
daw_zgł_krew_2544_K & 2012 & 3910 & 2837 & 82108 & 1023 & 10581 & $13.05 \%$ \\
daw_zgł_krew_2544_K & 2013 & 4081 & 2777 & 85711 & 1284 & 11267 & $13.62 \%$ \\
daw_zgł_krew_2544_K & 2014 & 4377 & 3487 & 91927 & 1431 & 11713 & $14.61 \%$ \\
daw_zgł_krew_2544_K & 2015 & 4675 & 3738 & 98170 & 1614 & 12620 & $15.60 \%$ \\
daw_zgł_krew_2544_K & 2016 & 4744 & 3734 & 99617 & 1470 & 12305 & $15.83 \%$ \\
daw_zgł_krew_2544_K & 2017 & 4677 & 3674 & 98227 & 1522 & 11914 & $15.61 \%$ \\
Total & & & & 629236 & & & $100 \%$ \\
\hline
\end{tabular}

daw_zgł_krew_2544_K - total number of female donors in the 25-44 age category

Table 41. Number of women aged 25-44 who reported for donation of blood/blood components in 2011-2017 broken down into RBTCs

\begin{tabular}{|c|c|c|c|c|c|c|c|}
\hline Variable & RBTC & Average & Median & Total & Min & Max & $\%$ total \\
\hline daw_zgł_krew_2544_K & Bialystok & 5131 & 5477 & 35918 & 3991 & 5747 & $5.71 \%$ \\
\hline daw_zgł_krew_2544_K & Bydgoszcz & 5358 & 5464 & 37504 & 4711 & 6011 & $5.96 \%$ \\
\hline daw_zgł_krew_2544_K & Gdansk & 4482 & 4602 & 31376 & 2714 & 5188 & $4.99 \%$ \\
\hline daw_zgł_krew_2544_K & Kalisz & 2766 & 2838 & 19360 & 2318 & 3107 & $3.08 \%$ \\
\hline daw_zgł_krew_2544_K & Katowice & 7891 & 7943 & 55239 & 6841 & 8786 & $8.78 \%$ \\
\hline daw_zgł_krew_2544_K & Kielce & 2413 & 2334 & 16893 & 1855 & 2935 & $2.68 \%$ \\
\hline daw_zgł_krew_2544_K & Krakow & 6997 & 6920 & 48976 & 6093 & 7736 & $7.78 \%$ \\
\hline daw_zgł_krew_2544_K & Lublin & 3392 & 3402 & 23743 & 2838 & 3738 & $3.77 \%$ \\
\hline daw_zgł_krew_2544_K & Lodz & 6039 & 6126 & 42275 & 5108 & 6910 & $6.72 \%$ \\
\hline daw_zgł_krew_2544_K & Olsztyn & 2964 & 3357 & 20746 & 1409 & 3734 & $3.30 \%$ \\
\hline daw_zgł_krew_2544_K & Opole & 1920 & 1920 & 13439 & 1752 & 2110 & $2.14 \%$ \\
\hline daw_zgł_krew_2544_K & Poznan & 7693 & 8310 & 53851 & 4199 & 8663 & $8.56 \%$ \\
\hline daw_zgł_krew_2544_K & Raciborz & 1597 & 1656 & 11177 & 1245 & 1779 & $1.78 \%$ \\
\hline daw_zgł_krew_2544_K & Radom & 1477 & 1470 & 10342 & 1220 & 1743 & $1.64 \%$ \\
\hline daw_zgł_krew_2544_K & Rzeszow & 2662 & 2537 & 18631 & 1042 & 3698 & $2.96 \%$ \\
\hline daw_zgł_krew_2544_K & Slupsk & 1331 & 1431 & 9314 & 640 & 1636 & $1.48 \%$ \\
\hline daw_zgł_krew_2544_K & Szczecin & 3433 & 3487 & 24030 & 2417 & 4053 & $3.82 \%$ \\
\hline daw_zgł_krew_2544_K & Walbrzych & 2363 & 2326 & 16543 & 2172 & 2550 & $2.63 \%$ \\
\hline daw_zgł_krew_2544_K & Warsaw & 11493 & 11713 & 80454 & 10054 & 12620 & $12.79 \%$ \\
\hline daw_zgł_krew_2544_K & Wroclaw & 6428 & 6616 & 44997 & 5455 & 7165 & $7.15 \%$ \\
\hline daw_zgł_krew_2544_K & Zielona Gora & 2061 & 2261 & 14428 & 1023 & 2678 & $2.29 \%$ \\
\hline Total & & & & 629236 & & & $100 \%$ \\
\hline
\end{tabular}

daw_zgł_krew_2544_K - total number of female donors in the 25-44 age category

blood supply and recipients' safety is widely discussed [4-7].

The analyses for Poland presented in this study demonstrate a reversal of trends predicting the increase or decrease in the number of donors in individual age categories. In group 1 , which covered the period 2005-2010, a clear upward trend was observed for the 18-30 and 31-45 age categories 
Table 42. Characteristics of the female population aged 45-65 who reported for donation of blood/blood components in 2011-2017 broken down into years

\begin{tabular}{lccccccc}
\hline Variable & Year & Average & Median & Total & Min & Max & $\%$ total \\
\hline daw_zgł_krew_4565_K & 2011 & 733 & 608 & 15394 & 209 & 1892 & $12.67 \%$ \\
daw_zgł_krew_4565_K & 2012 & 738 & 596 & 15495 & 227 & 1912 & $12.75 \%$ \\
daw_zgł_krew_4565_K & 2013 & 782 & 551 & 16428 & 246 & 1963 & $13.52 \%$ \\
daw_zgł_krew_4565_K & 2014 & 806 & 632 & 16919 & 275 & 1946 & $13.92 \%$ \\
daw_zgł_krew_4565_K & 2015 & 868 & 667 & 18220 & 266 & 1972 & $14.99 \%$ \\
daw_zgł_krew_4565_K & 2016 & 901 & 767 & 18925 & 326 & 2070 & $15.57 \%$ \\
daw_zgł_krew_4565_K & 2017 & 959 & 785 & 20149 & 324 & 2204 & $16.58 \%$ \\
Total & & & & 121530 & & & $100 \%$ \\
\hline
\end{tabular}

daw_zgł_krew_4565_K - total number of female donors in the $45-65$ age category

Table 43. Number of women aged 45-65 who reported for donation of blood/blood components in the years 2011-2017 broken down into RBTCs

\begin{tabular}{|c|c|c|c|c|c|c|c|}
\hline Variable & RBTC & Average & Median & Total & Min & Max & $\%$ total \\
\hline daw_zgł_krew_4565_K & Bialystok & 977 & 866 & 6841 & 596 & 1392 & $5.63 \%$ \\
\hline daw_zgł_krew_4565_k & Bydgoszcz & 1147 & 1116 & 8028 & 1007 & 1387 & $6.61 \%$ \\
\hline daw_zgł_krew_4565_k & Gdansk & 716 & 725 & 5012 & 632 & 785 & $4.12 \%$ \\
\hline daw_zgł_krew_4565_K & Kalisz & 698 & 702 & 4887 & 599 & 815 & $4.02 \%$ \\
\hline daw_zgł_krew_4565_k & Katowice & 1739 & 1781 & 12173 & 1379 & 1962 & $10.02 \%$ \\
\hline daw_zgł_krew_4565_k & Kielce & 496 & 480 & 3471 & 414 & 583 & $2.86 \%$ \\
\hline daw_zgł_krew_4565_k & Krakow & 1223 & 1171 & 8563 & 1150 & 1347 & $7.05 \%$ \\
\hline daw_zgł_krew_4565_K & Lublin & 613 & 608 & 4288 & 476 & 785 & $3.53 \%$ \\
\hline daw_zgł_krew_4565_k & Lodz & 1274 & 1239 & 8916 & 1117 & 1454 & $7.34 \%$ \\
\hline daw_zgł_krew_4565_K & Olsztyn & 598 & 616 & 4184 & 416 & 764 & $3.44 \%$ \\
\hline daw_zgł_krew_4565_k & Opole & 400 & 404 & 2801 & 356 & 440 & $2.30 \%$ \\
\hline daw_zgł_krew_4565_k & Poznan & 1223 & 1175 & 8561 & 1081 & 1446 & $7.04 \%$ \\
\hline daw_zgł_krew_4565_K & Raciborz & 461 & 461 & 3226 & 432 & 492 & $2.65 \%$ \\
\hline daw_zgł_krew_4565_k & Radom & 311 & 307 & 2178 & 257 & 364 & $1.79 \%$ \\
\hline daw_zgł_krew_4565_k & Rzeszow & 433 & 365 & 3034 & 248 & 608 & $2.50 \%$ \\
\hline daw_zgł_krew_4565_k & Slupsk & 268 & 266 & 1873 & 209 & 326 & $1.54 \%$ \\
\hline daw_zgł_krew_4565_k & Szczecin & 603 & 618 & 4220 & 396 & 767 & $3.47 \%$ \\
\hline daw_zgł_krew_4565_k & Walbrzych & 595 & 607 & 4163 & 545 & 631 & $3.43 \%$ \\
\hline daw_zgł_krew_4565_K & Warsaw & 1989 & 1963 & 13920 & 1892 & 2204 & $11.45 \%$ \\
\hline daw_zgł_krew_4565_k & Wroclaw & 1165 & 1177 & 8157 & 1030 & 1302 & $6.71 \%$ \\
\hline daw_zgł_krew_4565_k & Zielona Gora & 433 & 419 & 3034 & 361 & 547 & $2.50 \%$ \\
\hline Total & & & & 121530 & & & $100 \%$ \\
\hline
\end{tabular}

daw_zgł_krew_4565_K - total number of female donors in the 45-65 age category

with no distinctive trend observed for 46-65 age category. It may therefore be assumed that the latter group will remain relatively stable (app. 80 thousand donors per year). The predictions were confirmed by results for group 2 which covered the period 2011-2017. In the consecutive years, the 46-65 group was indeed estimated at 80000 donors per year. A disturbing trend was however observed 


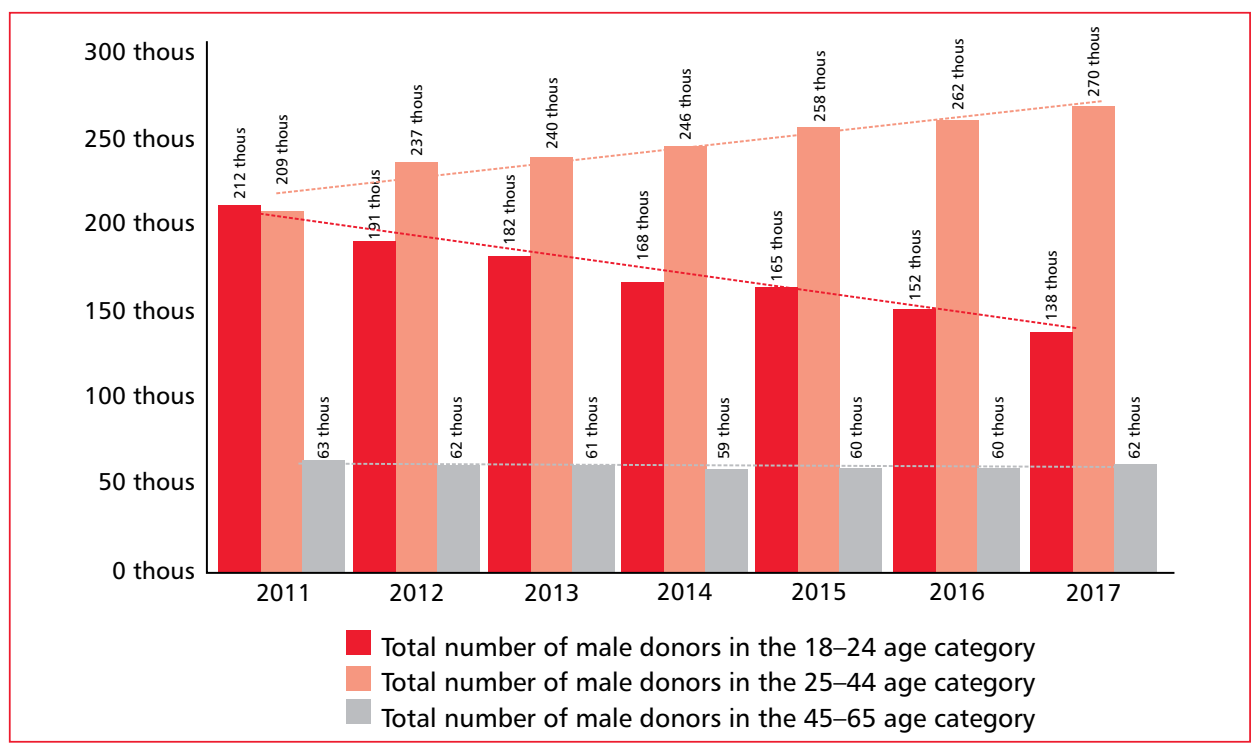

Figure 13. Number of men who reported at RBTCs to donate blood/blood components (2011-2017) broken down into age categories

Table 44. Characteristics of the male population aged 18-24 who reported for blood/blood component donation in 2011-2017 broken down into years

\begin{tabular}{lccccccc}
\hline Variable & Year & Average & Median & Total & Min & Max & $\%$ total \\
\hline daw_zgł_krew_1824_M & 2011 & 10103 & 9690 & 212162 & 3463 & 22085 & $17.55 \%$ \\
daw_zgł_krew_1824_M & 2012 & 9110 & 9325 & 191314 & 3064 & 16775 & $15.83 \%$ \\
daw_zgł_krew_1824_M & 2013 & 8673 & 8057 & 182129 & 2781 & 16134 & $15.07 \%$ \\
daw_zgł_krew_1824_M & 2014 & 7978 & 8253 & 167532 & 2679 & 15843 & $13.86 \%$ \\
daw_zgł_krew_1824_M & 2015 & 7868 & 7938 & 165225 & 2616 & 14907 & $13.67 \%$ \\
daw_zgł_krew_1824_M & 2016 & 7244 & 7741 & 152120 & 2360 & 13431 & $12.58 \%$ \\
daw_zgł_krew_1824_M & 2017 & 6587 & 6824 & 138323 & 2193 & 12560 & $11.44 \%$ \\
Total & & & & $\mathbf{1 2 0 8 8 0 5}$ & & & $100 \%$
\end{tabular}

daw_zgt_krew_1824_M - total number of male donors in the 18-24 age category

with regard to the youngest donor category (aged 18-24) from group 2 . The analyses demonstrate a clear downward trend and that must raise serious concern for the future. Although the middle aged population, i.e. $25-44$ still demonstrates an upward trend, nevertheless the projected decline for the youngest age category should motivate to implementation of decisive measures/actions in order to recruit more donors, particularly in the youngest age group.

Undoubtedly, more and more importance will be attributed to mechanisms of motivating people of all age categories to donate blood and become multiple donors, but attention should mostly be focused on the youngest generation, as this is the potential population to donate blood/blood components for many years to come.

Promotion of voluntary non-remunerated blood donation is of utmost importance with regard to the youngest citizens who may become blood donors in several years' time. In Poland, such promotion activities have been ongoing for several years, e.g. as part of the Health Policy Program "Ensuring the self-sufficiency of the Republic of Poland in the field of blood, blood components and blood products for the years 2015-2020". One of the program-objectives was promotion of voluntary non-remunerated blood donation as well as training and education. The action is targeted at adult citizens as well as elementary school children and high school youth [8]. 
Table 45. Number of men aged 18-24 who reported for donation of blood/blood components in the years 2011-2017 broken down into RBTCs

\begin{tabular}{|c|c|c|c|c|c|c|c|}
\hline Variable & RBTC & Average & Median & Total & Min & Max & $\%$ total \\
\hline daw_zgł_krew_1824_M & Bialystok & 8554 & 8804 & 59877 & 7311 & 10125 & $4.95 \%$ \\
\hline daw_zgł_krew_1824_M & Bydgoszcz & 9543 & 9709 & 66804 & 7946 & 10887 & $5.53 \%$ \\
\hline daw_zgł_krew_1824_M & Gdansk & 9393 & 8253 & 65751 & 7741 & 14489 & $5.44 \%$ \\
\hline daw_zgł_krew_1824_M & Kalisz & 5073 & 4926 & 35509 & 4842 & 5421 & $2.94 \%$ \\
\hline daw_zgł_krew_1824_M & Katowice & 12044 & 12137 & 84309 & 8324 & 14903 & $6.97 \%$ \\
\hline daw_zgł_krew_1824_M & Kielce & 5497 & 5424 & 38479 & 4827 & 5889 & $3.18 \%$ \\
\hline daw_zgł_krew_1824_M & Krakow & 14560 & 14805 & 101920 & 11385 & 17206 & $8.43 \%$ \\
\hline daw_zgł_krew_1824_M & Lublin & 9079 & 8995 & 63552 & 6824 & 10837 & $5.26 \%$ \\
\hline daw_zgł_krew_1824_M & Lodz & 11038 & 11206 & 77267 & 9538 & 12106 & $6.39 \%$ \\
\hline daw_zgł_krew_1824_M & Olsztyn & 6893 & 6419 & 48254 & 4552 & 11090 & $3.99 \%$ \\
\hline daw_zgł_krew_1824_M & Opole & 4674 & 4382 & 32716 & 3529 & 6080 & $2.71 \%$ \\
\hline daw_zgł_krew_1824_M & Poznan & 13894 & 12671 & 97255 & 11466 & 22085 & $8.05 \%$ \\
\hline daw_zgł_krew_1824_M & Raciborz & 4687 & 4095 & 32811 & 2990 & 8868 & $2.71 \%$ \\
\hline daw_zgł_krew_1824_M & Radom & 4051 & 4134 & 28360 & 3387 & 4551 & $2.35 \%$ \\
\hline daw_zgł_krew_1824_M & Rzeszow & 9057 & 8454 & 63400 & 7762 & 12659 & $5.24 \%$ \\
\hline daw_zgł_krew_1824_M & Slupsk & 3941 & 3888 & 27585 & 3138 & 5609 & $2.28 \%$ \\
\hline daw_zgł_krew_1824_M & Szczecin & 6723 & 6931 & 47063 & 5397 & 7620 & $3.89 \%$ \\
\hline daw_zgł_krew_1824_M & Walbrzych & 2737 & 2679 & 19156 & 2193 & 3463 & $1.58 \%$ \\
\hline daw_zgł_krew_1824_M & Warsaw & 15238 & 15843 & 106669 & 12560 & 17019 & $8.82 \%$ \\
\hline daw_zgł_krew_1824_M & Wroclaw & 10135 & 10142 & 70942 & 8561 & 11451 & $5.87 \%$ \\
\hline daw_zgł_krew_1824_M & Zielona Gora & 5875 & 5147 & 41126 & 4050 & 9325 & $3.40 \%$ \\
\hline Total & & & & 1208805 & & & $100 \%$ \\
\hline
\end{tabular}

daw_zgł_krew_1824_M - total number of male donors in the 18-24 age category

Table 46. Characteristics of the male population aged 25-44 who reported for donation of blood/blood components in 2011-2017, broken down into years

\begin{tabular}{lccccccc}
\hline Variable & Year & Average & Median & Total & Min & Max & $\%$ total \\
\hline daw_zgł_krew_2544_M & 2011 & 9964 & 8861 & 209253 & 2093 & 27066 & $12.15 \%$ \\
daw_zgł_krew_2544_M & 2012 & 11292 & 9411 & 237141 & 3830 & 27288 & $13.76 \%$ \\
daw_zgł_krew_2544_M & 2013 & 11452 & 9642 & 240498 & 3996 & 27558 & $13.96 \%$ \\
daw_zgł_krew_2544_M & 2014 & 11737 & 10287 & 246474 & 4128 & 27859 & $14.31 \%$ \\
daw_zgł_krew_2544_M & 2015 & 12270 & 11512 & 257674 & 4199 & 28493 & $14.96 \%$ \\
daw_zgł_krew_2544_M & 2016 & 12469 & 11326 & 261852 & 3930 & 28082 & $15.20 \%$ \\
daw_zgł_krew_2544_M & 2017 & 12856 & 12114 & 269971 & 4466 & 29326 & $15.67 \%$ \\
Total & & & & $\mathbf{1 7 2 2 8 6 3}$ & & & $100 \%$ \\
\hline
\end{tabular}

daw_zgł_krew_2544_M - total number of male donors in the 25-44 age category

The potential of the youngest group of citizens as future donors is also recognized in other countries. Finck et al. performed an analysis of factors motivating and potentially demotivating North American schoolchildren to donate blood. He found recruitment in this group of particular importance due to age and likelihood of becoming multiple donors and donating blood for many years to come. Moreover, this young population of potential donors is less likely to be deferred from donation due to disease or high-risk sexual behavior [9]. On the other hand, in their study of donors aged 16-17 (16 is the lower 
Table 47. Number of men aged 25-44 who reported for donation of blood/blood components in the years 2011-2017 , broken down into RBTCs

\begin{tabular}{|c|c|c|c|c|c|c|c|}
\hline Variable & RBTC & Average & Median & Total & Min & Max & $\%$ total \\
\hline daw_zgł_krew_2544_M & Bialystok & 11516 & 11571 & 80614 & 9642 & 13021 & $4.68 \%$ \\
\hline daw_zgł_krew_2544_M & Bydgoszcz & 13046 & 13035 & 91320 & 12341 & 14021 & $5.30 \%$ \\
\hline daw_zgł_krew_2544_M & Gdansk & 12114 & 12382 & 84795 & 7814 & 13572 & $4.92 \%$ \\
\hline daw_zgł_krew_2544_M & Kalisz & 7941 & 7976 & 55587 & 7226 & 8632 & $3.23 \%$ \\
\hline daw_zgł_krew_2544_M & Katowice & 26283 & 26984 & 183978 & 23564 & 27465 & $10.68 \%$ \\
\hline daw_zgł_krew_2544_M & Kielce & 6592 & 6477 & 46144 & 6081 & 7167 & $2.68 \%$ \\
\hline daw_zgł_krew_2544_M & Krakow & 18144 & 17703 & 127011 & 16957 & 19700 & $7.37 \%$ \\
\hline daw_zgł_krew_2544_M & Lublin & 11065 & 11326 & 77455 & 9875 & 12114 & $4.50 \%$ \\
\hline daw_zgł_krew_2544_M & Lodz & 14291 & 14429 & 100034 & 13155 & 15253 & $5.81 \%$ \\
\hline daw_zgł_krew_2544_M & Olsztyn & 8045 & 8698 & 56313 & 4373 & 9437 & $3.27 \%$ \\
\hline daw_zgł_krew_2544_M & Opole & 5690 & 5652 & 39827 & 5336 & 6046 & $2.31 \%$ \\
\hline daw_zgł_krew_2544_M & Poznan & 20110 & 21096 & 140772 & 12361 & 22619 & $8.17 \%$ \\
\hline daw_zgł_krew_2544_M & Raciborz & 7912 & 8314 & 55386 & 5297 & 8582 & $3.21 \%$ \\
\hline daw_zgł_krew_2544_M & Radom & 4033 & 3996 & 28233 & 3629 & 4466 & $1.64 \%$ \\
\hline daw_zgł_krew_2544_M & Rzeszow & 10428 & 10287 & 72994 & 4621 & 13391 & $4.24 \%$ \\
\hline daw_zgł_krew_2544_M & Slupsk & 4033 & 4199 & 28230 & 2093 & 4876 & $1.64 \%$ \\
\hline daw_zgł_krew_2544_M & Szczecin & 10127 & 10040 & 70888 & 8861 & 11215 & $4.11 \%$ \\
\hline daw_zgł_krew_2544_M & Walbrzych & 5419 & 5245 & 37935 & 5148 & 5837 & $2.20 \%$ \\
\hline daw_zgł_krew_2544_M & Warsaw & 27953 & 27859 & 195672 & 27066 & 29326 & $11.36 \%$ \\
\hline daw_zgł_krew_2544_M & Wroclaw & 15894 & 15624 & 111261 & 14247 & 17542 & $6.46 \%$ \\
\hline daw_zgł_krew_2544_M & Zielona Gora & 5488 & 6012 & 38414 & 3112 & 6765 & $2.23 \%$ \\
\hline Total & & & & 1722863 & & & $100 \%$ \\
\hline
\end{tabular}

daw_zgł_krew_2544_M - total number of male donors in the 25-44 age category

Table 48. Characteristics of the male population aged 45-65 who reported in RBTCs to donate blood/blood components in 2011-2017, broken down into years

\begin{tabular}{lccccccc}
\hline Variable & Year & Average & Median & Total & Min & Max & $\%$ total \\
\hline daw_zgł_krew_4565_M & 2011 & 3021 & 2643 & 63431 & 873 & 7473 & $14.84 \%$ \\
daw_zgł_krew_4565_M & 2012 & 2937 & 2197 & 61676 & 912 & 7112 & $14.43 \%$ \\
daw_zgł_krew_4565_M & 2013 & 2924 & 2399 & 61398 & 970 & 6923 & $14.37 \%$ \\
daw_zgł_krew_4565_M & 2014 & 2816 & 2380 & 59126 & 942 & 6577 & $13.84 \%$ \\
daw_zgł_krew_4565_M & 2015 & 2853 & 2548 & 59913 & 988 & 6470 & $14.02 \%$ \\
daw_zgł_krew_4565_M & 2016 & 2854 & 2538 & 59936 & 1003 & 6543 & $14.02 \%$ \\
daw_zgł_krew_4565_M & 2017 & 2946 & 2645 & 61875 & 1047 & 6625 & $14.48 \%$ \\
Total & & & & 427355 & & & $100 \%$ \\
\hline
\end{tabular}

daw_zgł_krew_4565_M - total number of male donors in the 45-65 age category

age limit for donors in the United States), Eder et al. report the highest likelihood of adverse reactions in this group as compared with other age groups of donors. According to their observations, donationrelated vasovagal reactions for those donors are
2.5 fold higher than in donors aged $18-19$ and 14.5 fold higher than for donors aged 20 or more. The youngest group of donors may therefore require additional care and attention during donation as well as after the procedure [10]. 
Table 49. Number of men aged 45-65 who reported to donate blood/blood components in 2011-2017, broken down into RBTCs

\begin{tabular}{|c|c|c|c|c|c|c|c|}
\hline Variable & RBTC & Average & Median & Total & Min & Max & $\%$ total \\
\hline daw_zgł_krew_4565_M & Bialystok & 2818 & 2852 & 19724 & 2197 & 3751 & $4.62 \%$ \\
\hline daw_zgł_krew_4565_M & Bydgoszcz & 3753 & 3686 & 26273 & 3607 & 4035 & $6.15 \%$ \\
\hline daw_zgł_krew_4565_M & Gdansk & 2627 & 2620 & 18391 & 2380 & 2912 & $4.30 \%$ \\
\hline daw_zgł_krew_4565_M & Kalisz & 2632 & 2645 & 18425 & 2538 & 2719 & $4.31 \%$ \\
\hline daw_zgł_krew_4565_M & Katowice & 6240 & 6108 & 43680 & 5831 & 6806 & $10.22 \%$ \\
\hline daw_zgł_krew_4565_M & Kielce & 2002 & 2040 & 14014 & 1883 & 2120 & $3.28 \%$ \\
\hline daw_zgł_krew_4565_M & Krakow & 4409 & 4421 & 30862 & 4238 & 4579 & $7.22 \%$ \\
\hline daw_zgł_krew_4565_M & Lublin & 2470 & 2533 & 17290 & 2193 & 2674 & $4.05 \%$ \\
\hline daw_zgł_krew_4565_M & Lodz & 3863 & 3863 & 27042 & 3619 & 4152 & $6.33 \%$ \\
\hline daw_zgł_krew_4565_M & Olsztyn & 1987 & 1930 & 13910 & 1710 & 2169 & $3.25 \%$ \\
\hline daw_zgł_krew_4565_M & Opole & 1499 & 1522 & 10490 & 1397 & 1606 & $2.45 \%$ \\
\hline daw_zgł_krew_4565_M & Poznan & 4242 & 4320 & 29693 & 3813 & 4734 & $6.95 \%$ \\
\hline daw_zgł_krew_4565_M & Raciborz & 1859 & 1796 & 13013 & 1675 & 2100 & $3.05 \%$ \\
\hline daw_zgł_krew_4565_M & Radom & 1232 & 1254 & 8624 & 1144 & 1281 & $2.02 \%$ \\
\hline daw_zgł_krew_4565_M & Rzeszow & 2519 & 2399 & 17636 & 2067 & 2922 & $4.13 \%$ \\
\hline daw_zgł_krew_4565_M & Slupsk & 962 & 970 & 6735 & 873 & 1047 & $1.58 \%$ \\
\hline daw_zgł_krew_4565_M & Szczecin & 2271 & 2281 & 15898 & 2032 & 2421 & $3.72 \%$ \\
\hline daw_zgł_krew_4565_M & Walbrzych & 1943 & 1926 & 13598 & 1791 & 2148 & $3.18 \%$ \\
\hline daw_zgł_krew_4565_M & Warsaw & 6807 & 6625 & 47646 & 6470 & 7473 & $11.15 \%$ \\
\hline daw_zgł_krew_4565_M & Wroclaw & 3397 & 3429 & 23777 & 3211 & 3475 & $5.56 \%$ \\
\hline daw_zgł_krew_4565_M & Zielona Gora & 1519 & 1443 & 10634 & 1406 & 1732 & $2.49 \%$ \\
\hline Total & & & & 427355 & & & $100 \%$ \\
\hline
\end{tabular}

daw_zgł_krew_4565_M - total number of male donors in the $45-65$ age category

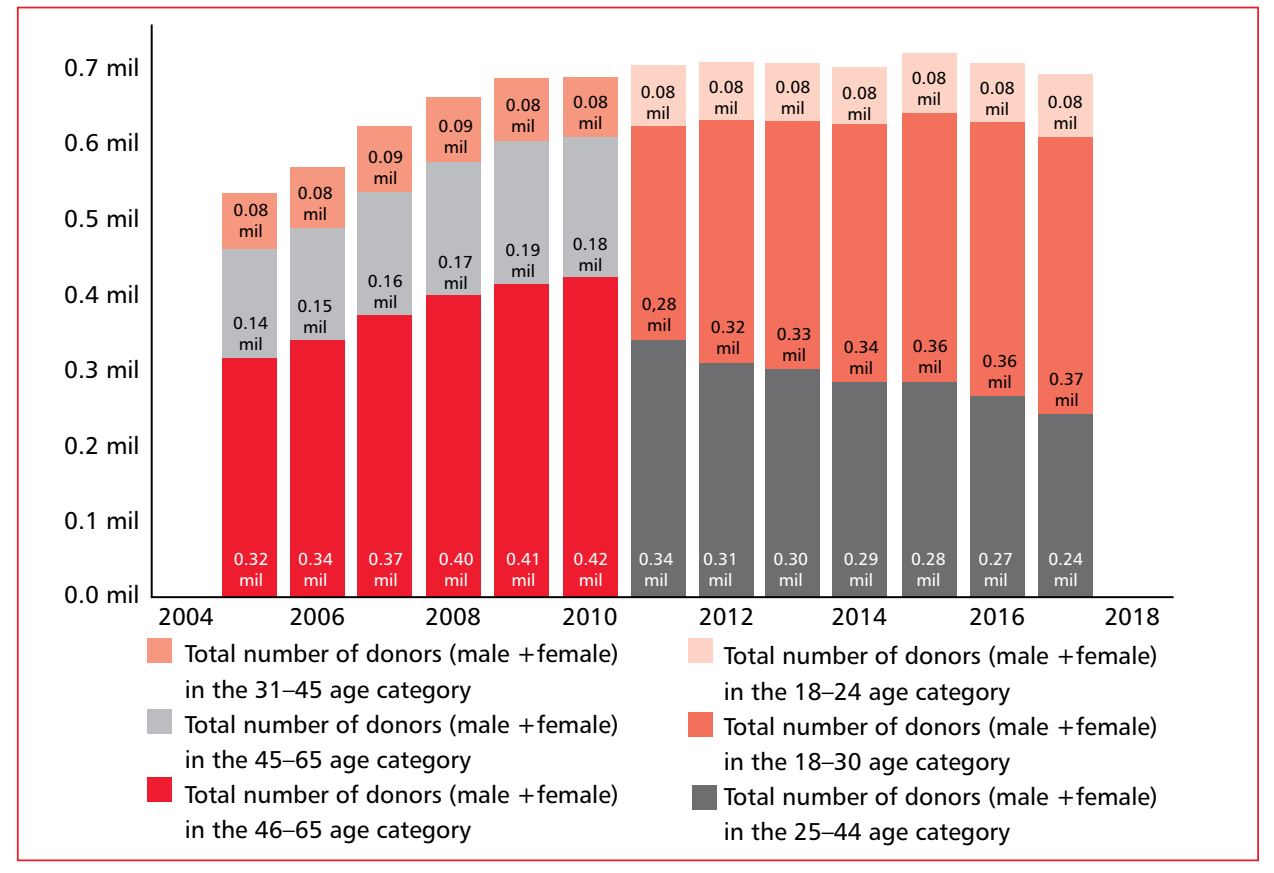

Figure 14. Comparison of data for donors who reported in RBTCs to donate blood/blood components in the periods 2005-2010 and 2011-2017, broken down into age categories 


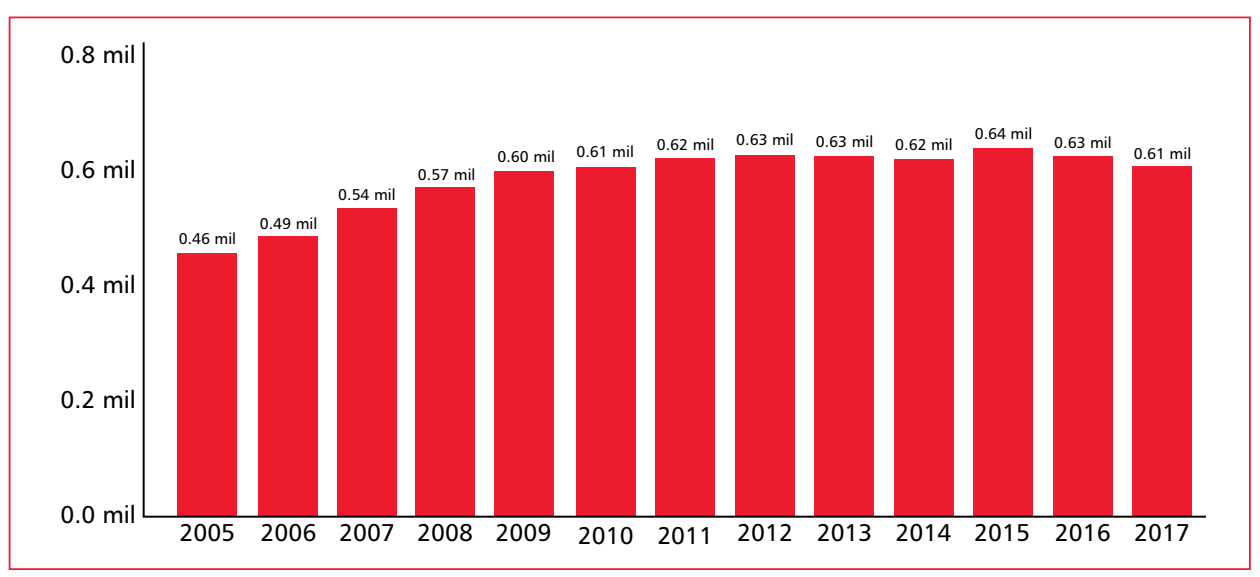

Figure 15. Number of donors in the 18-45 age category who reported at RBTCs to donate blood/blood components in the period 2005-2017

It is also advisable to take on measures to increase the number of women willing to donate blood. As presented in this study, for many years now the population of women in Poland has constituted $30-32 \%$ of the general donor population who report at RBTCs to donate blood/blood components. As indicated by WHO reports [11] the same trend is observed for other countries worldwide, nevertheless, it would be advisable to analyze the factors that demotivate women from donating blood. Currently in Poland less than $10 \%$ of women are multiple/regular blood donors.

Another challenge for Polish blood transfusion medicine is the recently growing number of foreigners with blood phenotypes unusual for the Polish population. According to the Central Statistical Office, in 2018 the number of immigrants for permanent residence amounted to 15461 , i.e. $>16 \%$ more than in 2017 (13 324) [12, 13]. Foreigners permanently living in Poland are on the one hand a source of potential donors, on the other - of potential recipients. As recipients, they may require transfusions of safe blood of atypical phenotypes for the Polish population and this is additional challenge. All the above considered, an in depth analysis of the phenomenon is required for estimation of the scale of the problem, and for taking appropriate actions, such as promotion to provide blood and blood components also for this group of Polish residents. Other countries are facing similar problems. In his study, Finck et al. found the donor population of young Americans to be interesting not only in terms of young age and potential for donation for years to come but because of ethnic diversity which reflects the diversity of the population of patients [9].
Activities of this kind require systematic analyses and targeted evidence-based intervention. This seems to be an ideal area for development of common approach of experts from various fields, including transfusion medicine, epidemiology and social sciences.

Alongside the growing significance of data processing which is being observed in the recent years, there is also a growing demand for effective analytical tools. Blood transfusion medicine seems to be the natural beneficiary of modern and effective analytical solutions $[14,15]$.

As result of computerization of the health care sector (blood transfusion service included), a huge amount of data is being generated and traditional tools have become insufficient for their analysis. Significance of multidimensional data analysis in the healthcare sector and the benefits which it brings about have already been recognized in other countries. Works are being published worldwide to demonstrate the potential use of advanced IT tools in the healthcare sector as well as tools for analysis of large and diverse data sets (Big Data and Data Mining) [16-19]. Sooner or later Poland will be following the same path and proceeding in the same direction.

Analysis of the huge amounts of data collected for the purpose of this study required the use of advanced analytical tools. For this purpose, Microsoft Power Business Intelligence (Power BI) software was introduced. Power BI is a set of tools for data analysis which, among others, allows to combine various data sources and prepare data for analysis (e.g. removal of unnecessary rows and columns, adjustment of data types or removal of repetitive/ /duplicate data). Furthermore, Power BI enables data transformation, e.g. column division, prepara- 
tion of aggregation, transposition and arithmetic calculations. Advanced visualization of large data sets is made possible.

This study may be considered as a starting point for other analyses of great significance for transfusion service, epidemiological analyses included. Detection of epidemiological threats/ /risks and strengthening of epidemiological control through performance of detailed statistical and spatial analysis of blood donor deferrals for HBV, HCV and HIV as well as Treponema pallidum will expand the knowledge on the epidemiological situation in Poland. The information will have direct impact on the health safety of the Polish population.

Another important approach relevant for prevention of deficiencies in blood and blood components, is effective management and optimal use of donated blood.

As already mentioned above, the study is a starting point for a series of publications based on retrospective data analysis and devoted to description of selected aspects of public blood transfusion service in Poland. The next publication will be a sequel with characteristics of donors who were found eligible to donate blood/blood components and indeed donated blood for clinical use. Publications to follow will present the structure and organization of the public blood transfusion service, description of donations collected over the study period and management of blood and blood components, with particular emphasis on red blood cell inventories.

\section{References}

1. Cianciara D. Nie ma zdrowia bez badań w dziedzinie zdrowia publicznego, Narodowy Instytut Zdrowia Publicznego - Państwowy Zakład Higieny; 2014.

2. Prognoza ludności na lata 2014-2050, Główny Urząd Statystyczny, Warszawa 2014, ISBN 978-83-7027-435-1.

3. Sytuacja demograficzna Polski do 2018 r. Tworzenie i rozpad rodzin, Główny Urząd Statystyczny, Warszawa 2019, ISBN 978-83-7027-719-2.

4. Greinacher A, Weitmann K, Schönborn L, et al. A population-based longitudinal study on the implication of demographic changes on blood donation and transfusion demand. Blood Adv. 2017; 1(14): 867-874, doi: 10.1182/bloodadvances.2017005876, indexed in Pubmed: 29296730.
5. Goldman M, Steele WR, Di Angelantonio E, et al. Biomedical Excellence for Safer Transfusion Collaborative (BEST) Investigators. Comparison of donor and general population demographics over time: a BEST Collaborative group study. Transfusion. 2017; 57(10): 2469-2476, doi: 10.1111/trf.14307, indexed in Pubmed: 28871601.

6. Müller-Steinhardt M, Weidmann C, Klüter H. Changes in the Whole Blood Donor Population in South-West Germany: 2010 versus 2016. Transfus Med Hemother. 2017; 44(4): 217-223, doi: 10.1159/000479192, indexed in Pubmed: 28924426.

7. Volken T, Buser A, Castelli D, et al. Red blood cell use in Switzerland: trends and demographic challenges. Blood Transfus. 2018; 16(1): 73-82, doi: 10.2450/2016.0079-16, indexed in Pubmed: 27723455.

8. https://www.gov.pl/web/zdrowie/zapewnienie-samowystarczalnosci-rp-w-krew-i-jej-skladniki.

9. Finck R, Ziman A, Hoffman M, et al. Motivating Factors and Potential Deterrents to Blood Donation in High School Aged Blood Donors. J Blood Transfus. 2016; 2016: 8624230, doi: 10.1155/2016/8624230, indexed in Pubmed: 27293985.

10. Eder AF, Crowder LA, Steele WR. Teenage blood donation: demographic trends, adverse reactions and iron balance. ISBT Science Series. 2017; 12(4): 395-400, doi: 10.1111/voxs.12377.

11. https://www.who.int/news-room/fact-sheets/detail/blood-safety-and-availability.

12. Rocznik Demograficzny, Główny Urząd Statystyczny, Warszawa 2018, ISSN 1505-6716.

13. Rocznik Demograficzny, Główny Urząd Statystyczny, Warszawa 2019, ISSN 1505-6716.

14. Batko K. , Możliwości wykorzystania Big Data w ochronie zdrowia, Roczniki Kolegium Analiz Ekonomicznych Szkoła Główna Handlowa. 2016; 42: 267-282.

15. Raport pn. „Trendy w polskiej ochronie zdrowia 2017”, PwC Polska; 2017.

16. Agarwal K, Gupta M, Gupta K, et al. Blood Transfusion System Using Data Mining Techniques and GRA. 2019 5th International Conference on Advanced Computing \& Communication Systems (ICACCS). 2019, doi: 10.1109/icaccs.2019.8728401.

17. Dash S, Shakyawar S, Sharma M, et al. Big data in healthcare: management, analysis and future prospects. Journal of Big Data. 2019; 6(1), doi: 10.1186/s40537-019-0217-0.

18. Wang Y, Kung L, Byrd T. Big data analytics: Understanding its capabilities and potential benefits for healthcare organizations. Technological Forecasting and Social Change. 2018; 126: 3-13, doi: 10.1016/j.techfore.2015.12.019.

19. Guan L, Tian X, Gombar S, et al. Big data modeling to predict platelet usage and minimize wastage in a tertiary care system. Proc Natl Acad Sci U S A. 2017; 114(43): 11368-11373, doi: 10.1073/ /pnas.1714097114, indexed in Pubmed: 29073058. 